NOTICE: this is the author's version of a work that was accepted for publication in The Journal of Chemical Thermodynamics. Changes resulting from the publishing process, such as peer review, editing, corrections, structural formatting, and other quality control mechanisms may not be reflected in this document. Changes may have been made to this work since it was submitted for publication. A definitive version was subsequently published in The Journal of Chemical Thermodynamics, Vol. 78 (2014).

DOI: $10.1016 /$ j.jct.2014.06.013 


\title{
Thermodynamic Consistencies and Anomalies among End-member Lanthanoid Garnets
}

\author{
Leslie Glasser* \\ Nanochemistry Research Institute, Department of Chemistry, \\ Curtin University, GPO Box U1987, Perth WA 6845, Australia
}

8 Figures

3 Tables

Supplementary Figures S1a-S1f and S2a-S2f

Keywords: Thermodynamics; solid state; ionic materials; garnets; lanthanoids;

lanthanides

*Corresponding author

L. Glasser: $\quad$ Telephone: + 618 9266-3126 Fax: + 618 9266-4699

E-mail: 1.glasser@curtin.edu.au 


\begin{abstract}
Lanthanoid (or lanthanide) garnets are ionic solids of technological importance in their use as laser materials. They are also of interest in respect of their systematic relationships and as geochemical tracers. As a consequence, there is considerable published thermodynamic information for these garnets.
\end{abstract}

Based principally on the computational results of Moretti and Ottonello (1998), we here examine the thermodynamic information for consistencies and anomalies among the ferri-, alumino-, and gallo-garnets using relations between thermodynamic properties that we have established over recent years. The principal properties of interest are formula volume, heat capacity, entropy, and formation enthalpy (from which the Gibbs energy may be obtained), and isothermal compressibility. We also establish additive single-ion values for trivalent lanthanide cations which may be applied in estimating properties for related materials.

Since the results of the work of Moretti and Ottonello are based upon consistent computational analyses, we should expect generally smooth relations. These are, indeed, found for various of the properties (except for the europium garnets), with some uncertainty in the absolute entropies, and anomalies in the formation enthalpies of europium and ytterbium/lutetium garnets. The results of some more recent experimental work are included in our analyses. Values for the (unknown) promethium garnets are estimated by averaging the properties of the neighbouring neodymium and samarium garnets. 


\section{Introduction}

Over the past two decades and more, colleagues and I have established a number of useful relations among the thermophysical properties of ionic solids, principally based on the fact that the energetics of ionic solids are essentially controlled by the long-range charge (coulombic) interactions opposed by the short-range repulsions, with only small contributions from other interactions [1]. Furthermore, the standard thermodynamic quantities (such as heat capacity, entropy, and enthalpy) of these materials are integrals over their frequency distributions so that the values generated are insensitive to details of the phonon spectrum [2] and thus largely independent of crystal structural details [3]. These considerations result in reliable correlations among the thermophysical properties, the charges involved, and the formula volumes of the materials, corresponding to a "Volume-Based Thermodynamics" (VBT) [4; 5].

Although the lanthanides are not much involved in basic research (and often thus regarded as rare-earth elements), they quite abundant in nature and may play an increasing role in technological applications. Garnets containing lanthanide cations (with general chemical formula $\mathrm{Ln}_{3} \mathrm{M}_{5} \mathrm{O}_{12}$ ) receive considerable thermodynamic attention because of their importance for the laser industry (consider the ubiquity of $\mathrm{Nd}$ :YAG lasers - that is, lasers based on $\mathrm{Nd}$-doped yttrium aluminium garnet material, $\mathrm{Y}_{3} \mathrm{Al}_{5} \mathrm{O}_{12}$ ). They are also of interest in respect of their systematic relationships [6] and as geochemical tracers [7]. However, the behaviours of these lanthanides are not always straightforward: for example, while most exist only as trivalent ions, $\mathrm{Ln}^{3+}$, Eu also can take on divalency while Ce can be quadrivalent, leading to their enrichment or depletion 
in minerals relative to the other rare-earths - these are the so-called Europium and Cerium anomalies [7]. The current paper examines the thermodynamics of a large number of lanthanoid (often called lanthanide) garnets by means of VBT and other relations

The lanthanoid garnets form in the crystal-structure space group $\operatorname{Ia} \overline{\mathbf{3}} \boldsymbol{d}$, with the $f$-block

$\mathrm{Ln}^{3+}$ cations eight-coordinated to oxygen in distorted cubes, and with $\mathrm{M}^{3+}$ both octahedrally six-coordinated to oxygen and tetrahedrally four-coordinated to oxygen. The cations all lie in symmetry-controlled positions, with only oxygen having variable fractional coordinates.

\section{Thermodynamic Properties}

The physico-chemical properties of lanthanoid garnets have received considerable attention, with their advantage of providing a closely-homologous group among which relationships may be examined in detail. Their spectroscopic [6] and thermodynamic [8] properties have been thoroughly examined and reported, and we here use the important thermodynamic data together with other data in considering correlations among these properties.

The principal properties of interest are formula volume, heat capacity, entropy, and formation enthalpy (from which the Gibbs energy may be obtained), and isothermal compressibility. Table 1 contains corresponding data for the lanthanoid ferri-, alumino-, and gallo-garnets. A noticeable feature in the Table is the closeness of the ratio $C_{\mathrm{p}} / S$ to 
unity, i. e., ambient heat capacities and entropies are closely equal [3]. Much of our results are derived from the consistent computational analyses of Moretti and Ottonello [8], we should expect generally smooth relations - with some discrepancies based upon particular properties of the constituent lanthanide ion. 
Table 1: Formation enthalpy, absolute entropy, molar formula volume, heat capacity, isothermal compressibility, lattice energy of lanthanoid garnets [8], and ratio of heat capacity to entropy. Values for the unknown promethium garnets are linear interpolations.

\begin{tabular}{|c|c|c|c|c|c|c|c|c|c|c|}
\hline $\begin{array}{c}\text { Lanthanoid } \\
\text { Garnets }\end{array}$ & $\begin{array}{c}\Delta_{\mathrm{f}} H \\
/ \mathrm{kJ} \mathrm{mol}^{-1}\end{array}$ & $\begin{array}{c}S \\
/ \mathrm{J} \mathrm{K}^{-1} \mathrm{~mol}^{-1}\end{array}$ & $\begin{array}{c}s^{\mathrm{b}} \\
/ \mathrm{J} \mathrm{K}^{-1} \mathrm{~mol}^{-1}\end{array}$ & $\begin{array}{c}V_{\mathrm{m}} \\
/ \mathrm{nm}^{3}\end{array}$ & $\begin{array}{c}C_{\mathrm{p}} \\
/ \mathrm{J} \mathrm{K}^{-1} \mathrm{~mol}^{-1}\end{array}$ & $\begin{array}{c}\mathrm{C}_{\mathrm{p}}^{\mathrm{b}} \\
/ \mathrm{J} \mathrm{K}^{-1} \mathrm{~mol}^{-1}\end{array}$ & $\begin{array}{l}10^{3} \times \beta \\
/ \mathrm{GPa}^{-1}\end{array}$ & $\begin{array}{c}U_{\text {POT }} \\
/ \mathrm{kJ} \mathrm{mol}^{-1}\end{array}$ & $\begin{array}{c}\boldsymbol{U}_{\mathrm{POT}}(\text { limiting })^{\mathrm{c}} \\
/ \mathrm{kJ} \mathrm{mol}^{-1}\end{array}$ & $C p / S$ \\
\hline $\mathrm{Y}_{3} \mathrm{Fe}_{5} \mathrm{O}_{12}$ & -5085.9 & 394.0 & & 0.237 & 411.0 & & 6.20 & -56358 & -58529 & 1.04 \\
\hline $\mathrm{La}_{3} \mathrm{Fe}_{5} \mathrm{O}_{12}{ }^{\mathrm{a}}$ & -4704.8 & 424.4 & & 0.258 & 417.8 & & 6.75 & -55124 & -56906 & 0.98 \\
\hline $\mathrm{Ce}_{3} \mathrm{Fe}_{5} \mathrm{O}_{12}{ }^{\mathrm{a}}$ & -4701.3 & 421.6 & & 0.255 & 415.7 & & 6.68 & -55247 & -57082 & 0.99 \\
\hline $\mathrm{Pr}_{3} \mathrm{Fe}_{5} \mathrm{O}_{12}$ & -4754.2 & 418.3 & & 0.253 & 414.2 & & 6.64 & -55398 & -57256 & 0.99 \\
\hline $\mathrm{Nd}_{3} \mathrm{Fe}_{5} \mathrm{O}_{12}$ & -4828.9 & 414.8 & & 0.250 & 413.7 & & 6.54 & -55577 & -57470 & 1.00 \\
\hline $\mathrm{Pm}_{3} \mathrm{Fe}_{5} \mathrm{O}_{12}$ & -4913 & 412 & & 0.248 & 413 & & 6.49 & -55689 & -57615 & 1.00 \\
\hline $\mathrm{Sm}_{3} \mathrm{Fe}_{5} \mathrm{O}_{12}$ & -4997.3 & 408.8 & 435.1 & 0.246 & 412.1 & 450.8 & 6.44 & -55801 & -57761 & 1.01 \\
\hline $\mathrm{Eu}_{3} \mathrm{Fe}_{5} \mathrm{O}_{12}$ & -4720.1 & 408.0 & 432.2 & 0.245 & 412.8 & 467.6 & 6.42 & -55879 & -57864 & 1.01 \\
\hline $\mathrm{Gd}_{3} \mathrm{Fe}_{5} \mathrm{O}_{12}$ & -4994.3 & 405.9 & 450.8 & 0.242 & 410.7 & 433.0 & 6.33 & -56031 & -58083 & 1.01 \\
\hline $\mathrm{Tb}_{3} \mathrm{Fe}_{5} \mathrm{O}_{12}$ & -5030.2 & 419.3 & 446.9 & 0.241 & 411.7 & 432.2 & 6.32 & -56099 & -58197 & 0.98 \\
\hline $\mathrm{Dy}_{3} \mathrm{Fe}_{5} \mathrm{O}_{12}$ & -5012.1 & 416.7 & 427.3 & 0.239 & 410.3 & 426.2 & 6.26 & -56230 & -58391 & 0.98 \\
\hline $\mathrm{Ho}_{3} \mathrm{Fe}_{5} \mathrm{O}_{12}$ & -5038.3 & 414.7 & 473.1 & 0.237 & 409.1 & 445.7 & 6.20 & -56302 & -58509 & 0.99 \\
\hline $\mathrm{Er}_{3} \mathrm{Fe}_{5} \mathrm{O}_{12}$ & -5044.9 & 412.8 & 483.9 & 0.235 & 407.9 & 428.0 & 6.15 & -56339 & -58657 & 0.99 \\
\hline $\mathrm{Tm}_{3} \mathrm{Fe}_{5} \mathrm{O}_{12}$ & -5016.3 & 411.3 & & 0.234 & 409.2 & & 6.11 & -56456 & -58773 & 0.99 \\
\hline $\mathrm{Yb}_{3} \mathrm{Fe}_{5} \mathrm{O}_{12}$ & -4879.1 & 393.2 & & 0.233 & 407.2 & & 6.08 & -56517 & -58879 & 1.04 \\
\hline
\end{tabular}




\begin{tabular}{|c|c|c|c|c|c|c|c|c|}
\hline $\mathrm{Lu}_{3} \mathrm{Fe}_{5} \mathrm{O}_{12}$ & -4967.7 & 391.1 & 0.231 & 407.1 & 6.05 & -56580 & -58994 & 1.04 \\
\hline $\mathrm{Y}_{3} \mathrm{Al}_{5} \mathrm{O}_{12}$ & -7159.0 & 305.2 & 0.216 & 356.6 & 5.59 & -57200 & -59879 & 1.17 \\
\hline $\mathrm{La}_{3} \mathrm{Al}_{5} \mathrm{O}_{12}{ }^{\mathrm{a}}$ & -6564.2 & 314.3 & 0.235 & 369.2 & 6.03 & -55752 & -58229 & 1.17 \\
\hline $\mathrm{Ce}_{3} \mathrm{Al}_{5} \mathrm{O}_{12}{ }^{\mathrm{a}}$ & -6589.2 & 323.2 & 0.233 & 367.4 & 6.00 & -55898 & -58405 & 1.14 \\
\hline $\mathrm{Pr}_{3} \mathrm{Al}_{5} \mathrm{O}_{12}$ & -6660.1 & 324.2 & 0.231 & 366.0 & 5.95 & -56073 & -58581 & 1.13 \\
\hline $\mathrm{Nd}_{3} \mathrm{Al}_{5} \mathrm{O}_{12}$ & -6765.6 & 323.0 & 0.228 & 364.2 & 5.88 & -56282 & -58802 & 1.13 \\
\hline $\mathrm{Pm}_{3} \mathrm{Al}_{5} \mathrm{O}_{12}$ & -6869 & 320 & 0.226 & 363 & 5.83 & -56414 & -58948 & 1.13 \\
\hline $\mathrm{Sm}_{3} \mathrm{Al}_{5} \mathrm{O}_{12}$ & -6972.9 & 317.7 & 0.225 & 362.0 & 5.79 & -56546 & -59096 & 1.14 \\
\hline $\mathrm{Eu}_{3} \mathrm{Al}_{5} \mathrm{O}_{12}$ & -6708.4 & 306.2 & 0.224 & 361.2 & 5.77 & -56636 & -59198 & 1.18 \\
\hline $\mathrm{Gd}_{3} \mathrm{Al}_{5} \mathrm{O}_{12}$ & -7010.7 & 316.9 & 0.221 & 359.4 & 5.70 & -56816 & -59424 & 1.13 \\
\hline $\mathrm{Tb}_{3} \mathrm{Al}_{5} \mathrm{O}_{12}$ & -7059.1 & 319.0 & 0.220 & 358.6 & 5.68 & -56897 & -59538 & 1.12 \\
\hline $\mathrm{Dy}_{3} \mathrm{Al}_{5} \mathrm{O}_{12}$ & -7064.4 & 318.9 & 0.218 & 357.2 & 5.64 & -57051 & -59735 & 1.12 \\
\hline $\mathrm{Ho}_{3} \mathrm{Al}_{5} \mathrm{O}_{12}$ & -7104.5 & 319.3 & 0.216 & 356.6 & 5.60 & -57137 & -59854 & 1.12 \\
\hline $\mathrm{Er}_{3} \mathrm{Al}_{5} \mathrm{O}_{12}$ & -7129.5 & 315.6 & 0.215 & 354.6 & 5.56 & -57242 & -60005 & 1.12 \\
\hline $\mathrm{Tm}_{3} \mathrm{Al}_{5} \mathrm{O}_{12}$ & -7112.4 & 314.6 & 0.213 & 354.3 & 5.53 & -57320 & -60125 & 1.13 \\
\hline $\mathrm{Yb}_{3} \mathrm{Al}_{5} \mathrm{O}_{12}$ & -6987.9 & 312.3 & 0.212 & 354.0 & 5.52 & -57395 & -60231 & 1.13 \\
\hline $\mathrm{Lu}_{3} \mathrm{Al}_{5} \mathrm{O}_{12}$ & -7089.0 & 298.3 & 0.211 & 352.8 & 5.48 & -57470 & -60353 & 1.18 \\
\hline $\mathrm{Y}_{3} \mathrm{Ga}_{5} \mathrm{O}_{12}$ & -5718.8 & 360.2 & 0.231 & 387.4 & 6.03 & -57457 & -58529 & 1.08 \\
\hline $\mathrm{La}_{3} \mathrm{Ga}_{5} \mathrm{O}_{12}{ }^{\mathrm{a}}$ & -5246.4 & 371.4 & 0.252 & 397.8 & 6.57 & -56132 & -56906 & 1.07 \\
\hline $\mathrm{Ce}_{3} \mathrm{Ga}_{5} \mathrm{O}_{12}{ }^{\mathrm{a}}$ & -5258.7 & 380.0 & 0.249 & 396.3 & 6.51 & -56265 & -57082 & 1.04 \\
\hline
\end{tabular}




\begin{tabular}{|l|l|l|l|l|l|l|l|l|l|l|}
\hline $\mathrm{Pr}_{3} \mathrm{Ga}_{5} \mathrm{O}_{12}$ & -5314.9 & 380.7 & & 0.247 & 395.2 & & 6.44 & -56425 & -57256 & 1.04 \\
\hline $\mathrm{Na}_{3} \mathrm{Ga}_{5} \mathrm{O}_{12}$ & -5403.9 & 379.0 & & 0.244 & 393.5 & & 6.37 & -56618 & -57470 & 1.04 \\
\hline $\mathrm{Pm}_{3} \mathrm{Ga}_{5} \mathrm{O}_{12}$ & -5496 & 376 & & 0.242 & 392 & & 6.32 & -56739 & -57615 & 1.04 \\
\hline $\mathrm{Sm}_{3} \mathrm{Ga}_{5} \mathbf{O}_{12}$ & -5588.4 & 373.5 & & 0.241 & 391.4 & & 6.26 & -56859 & -57761 & 1.05 \\
\hline $\mathrm{Eu}_{3} \mathrm{Ga}_{5} \mathrm{O}_{12}$ & -5316.1 & 361.1 & & 0.239 & 390.6 & & 6.24 & -56941 & -57864 & 1.08 \\
\hline $\mathrm{Gd}_{3} \mathrm{Ga}_{5} \mathrm{O}_{12}$ & -5602.6 & 371.2 & & 0.237 & 389.1 & & 6.17 & -57106 & -58083 & 1.05 \\
\hline $\mathrm{Tb}_{3} \mathrm{Ga}_{5} \mathrm{O}_{12}$ & -5644.2 & 373.5 & & 0.235 & 388.4 & & 6.13 & -57180 & -58197 & 1.04 \\
\hline $\mathrm{Dy}_{3} \mathrm{Ga}_{5} \mathrm{O}_{12}$ & -5637.2 & 372.1 & & 0.233 & 387.0 & & 6.07 & -57321 & -58391 & 1.04 \\
\hline $\mathrm{Ho}_{3} \mathrm{Ga}_{5} \mathbf{O}_{12}$ & -5669.6 & 374.1 & & 0.232 & 387.3 & & 6.02 & -57400 & -58509 & 1.04 \\
\hline $\mathrm{Er}_{3} \mathrm{Ga}_{5} \mathrm{O}_{12}$ & -5685.3 & 370.3 & & 0.230 & 385.5 & & 5.97 & -57496 & -58657 & 1.04 \\
\hline $\mathrm{Tm}_{3} \mathrm{Ga}_{5} \mathrm{O}_{12}$ & -5661.1 & 367.1 & & 0.228 & 384.0 & & 5.95 & -57567 & -58773 & 1.05 \\
\hline $\mathrm{Yb}_{3} \mathrm{Ga}_{5} \mathrm{O}_{12}$ & -5530.9 & 366.7 & & 0.227 & 384.5 & & 5.91 & -57636 & -58879 & 1.05 \\
\hline $\mathbf{L u}_{3} \mathrm{Ga}_{5} \mathrm{O}_{12}$ & -5623.8 & 350.7 & & 0.226 & 382.8 & & 5.88 & -57703 & -58994 & 1.09 \\
\hline
\end{tabular}

${ }^{\mathrm{a}} \mathrm{La}$ and Ce garnets are not stable under ambient conditions. Promethium is not known in nature.

${ }^{\mathrm{b}}$ Reference [9].

${ }^{\mathrm{c}} U_{\mathrm{POT}}$ (limiting) values for the gallogarnets from $\mathrm{Nd}_{3} \mathrm{Ga}_{5} \mathrm{O}_{12}$ to $\mathrm{Lu}_{3} \mathrm{Ga}_{5} \mathrm{O}_{12}$ have earlier been reported by Petrov, in a corrected version [10]. There are slight differences between those published and the values listed here on account of small differences in the reference values used. 
We initiate examination of the data by considering systematic relations. As a preliminary example, Fig. 1 plots the formula volumes of the alumino-, ferro- and gallo-rare earth garnets. The expected systematic variation associated with the decreasing volumes of the later lanthanide ions is clear, together with the smaller volume of the $\mathrm{Y}^{3+}$ ion.

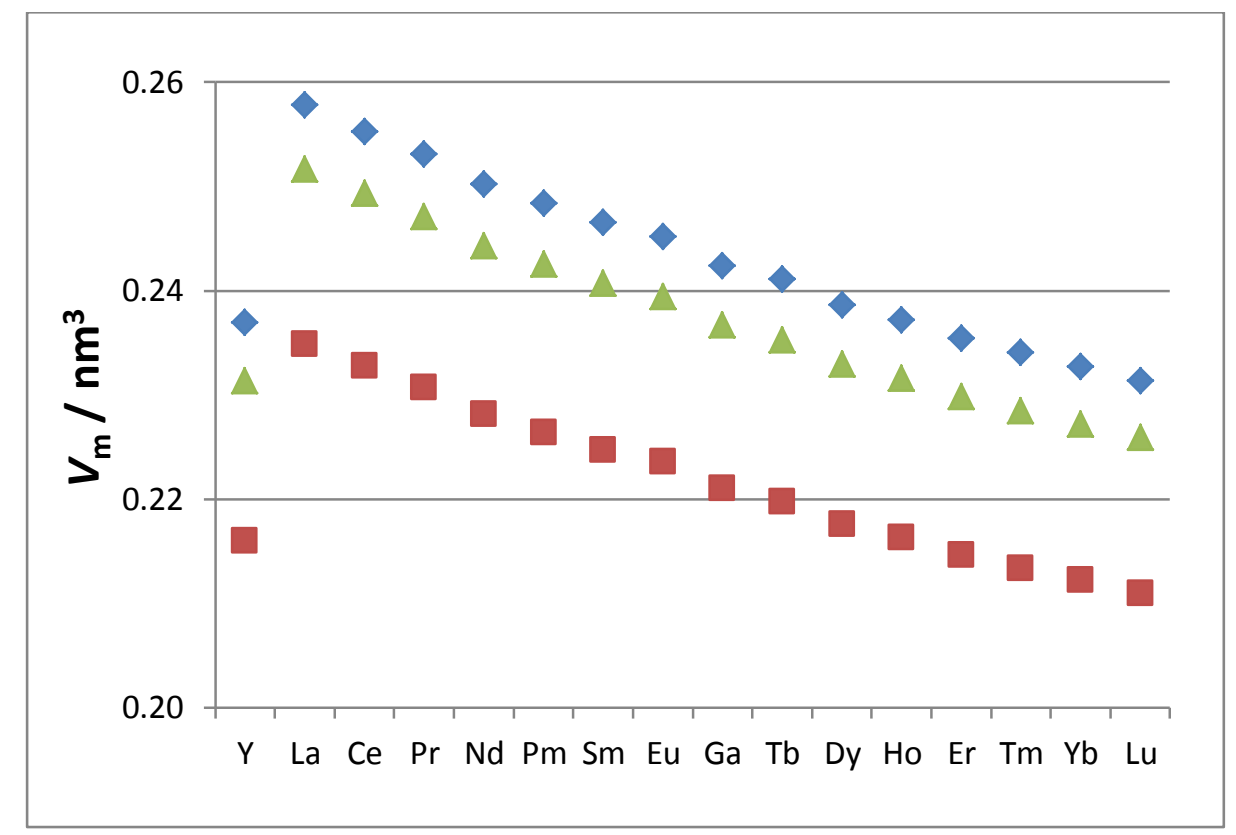

Figure 1: Ambient formula volume, $V_{\mathrm{m}} / \mathrm{nm}^{3}$, of lanthanoid garnets plotted against atomic number. Red squares: $\mathrm{Ln}_{3} \mathrm{Al}_{5} \mathrm{O}_{12}$; blue diamonds: $\mathrm{Ln}_{3} \mathrm{Fe}_{5} \mathrm{O}_{12}$; green triangles: $\mathrm{Ln}_{3} \mathrm{Ga}_{5} \mathrm{O}_{12}$.

Supplementary Figures S1a to S1f represent data for formula volume, isochoric heat capacity, absolute entropy, formation enthalpy, lattice energy, and isothermal compressibility, respectively, while Supplementary Figures S2a to S2f represent additive single-ion values for the same properties. (Fig. S1a duplicates Fig. 1 for ease of comparison within the Supplementary Figures.) Since the curves depicted are generally smooth without remarkable features, as for Fig. 1, these Figures are relegated to the 
Supplementary Information, but those Figures with anomalous results appear also in the main text. The values for the unknown promethium $(\mathrm{Pm})$ garnets in Table 1 have been estimated as simply the mean of the values of their immediately adjacent neighbours, $\mathrm{Nd}$ and Sm, given the generally smooth data curves observed in the Supplementary Figures. The data points for the yttrium garnets in Table 2 divert from the general run since they are not true members of the lanthanide series. The single-ion values of all these materials will be discussed in more detail below.

It is noticeable that the values for the europium garnets are somewhat anomalous. This is principally because the ground state for $\mathrm{Eu}^{3+}$ is ${ }^{7} \mathrm{~F}_{0}$, with zero magnetic spin entropy, whereas the other trivalent lanthanide ions have finite values of their magnetic spin entropies (cf. Table 10 [8]). Effects of this ground-state property may be observed for the formation enthalpy in Fig. 2. There is also a noticeable discrepancy between the formation enthalpy of the $\mathrm{Yb}$ garnets and the neighbouring Lu garnets. This results from a fall in the ionization energy of the $\mathrm{Lu}^{3+}$ ion relative to that of the $\mathrm{Yb}^{3+}$ ion where the latter has a fully-shielded outer electron shell ([Xe]4f $f^{14}$, cf. Fig. 6 of Moretti and Ottonello [8]). 


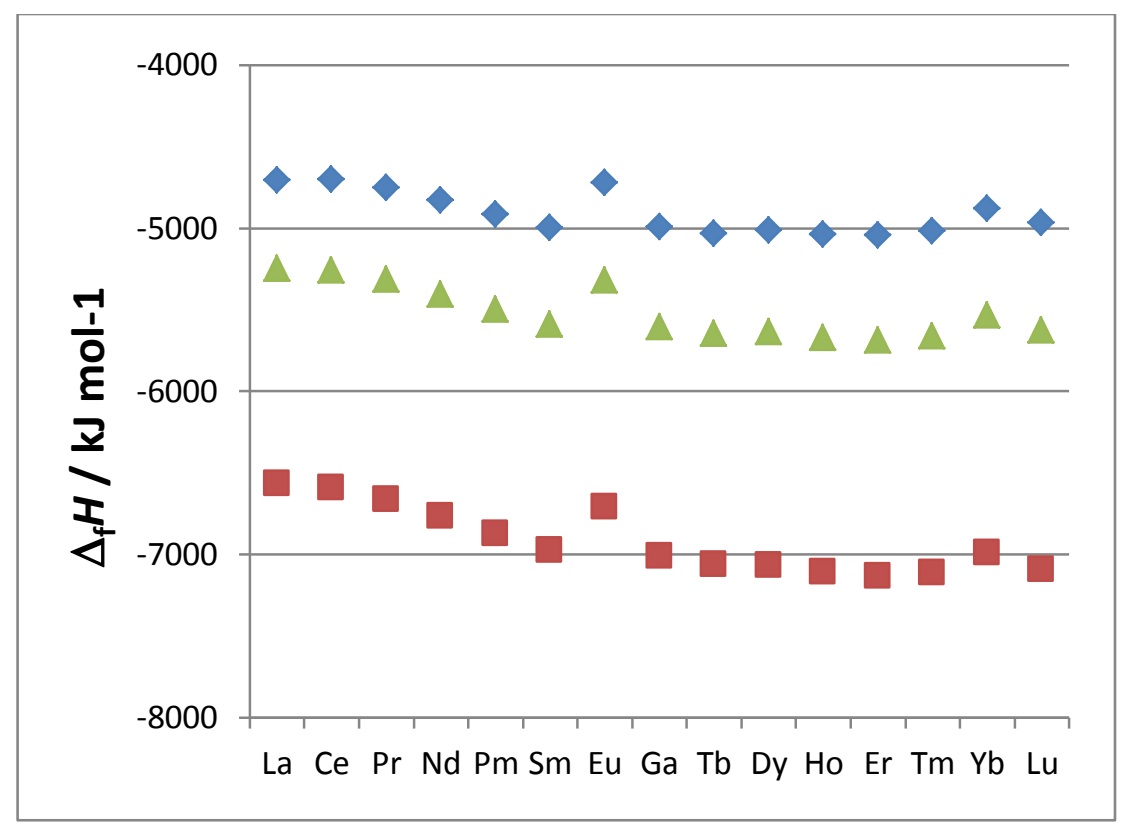

Figure 2: Ambient formation enthalpy, $\Delta_{f} H / \mathrm{kJ} \mathrm{mol}^{-1}$, of lanthanoid garnets plotted against atomic number. Red squares: $\mathrm{Ln}_{3} \mathrm{Al}_{5} \mathrm{O}_{12}$; blue diamonds: $\mathrm{Ln}_{3} \mathrm{Fe}_{5} \mathrm{O}_{12}$; green triangles: $\mathrm{Ln}_{3} \mathrm{Ga}_{5} \mathrm{O}_{12}$. (This Figure is duplicated as Fig. S1d in the Supplementary Information.)

\section{Thermodynamic Correlations}

The apparently smooth general relations become more valuable when they are combined in correlations that have been earlier established for ionic solids $[5 ; 11]$.

There is a general tendency of the heat capacities to increase with formula volume (Fig. 3). This agrees with earlier observations [12] that heat capacity is roughly proportional to formula volume, noting that the expanded scales of the current plot emphasises the deviations from strict proportionality. The experimental values for the ferrigarnets reported by Parida, et al. [9] are some 10\% larger than the the fitted values of Moretti and Ottonello [8] and do not follow a clearly consistent pattern. 


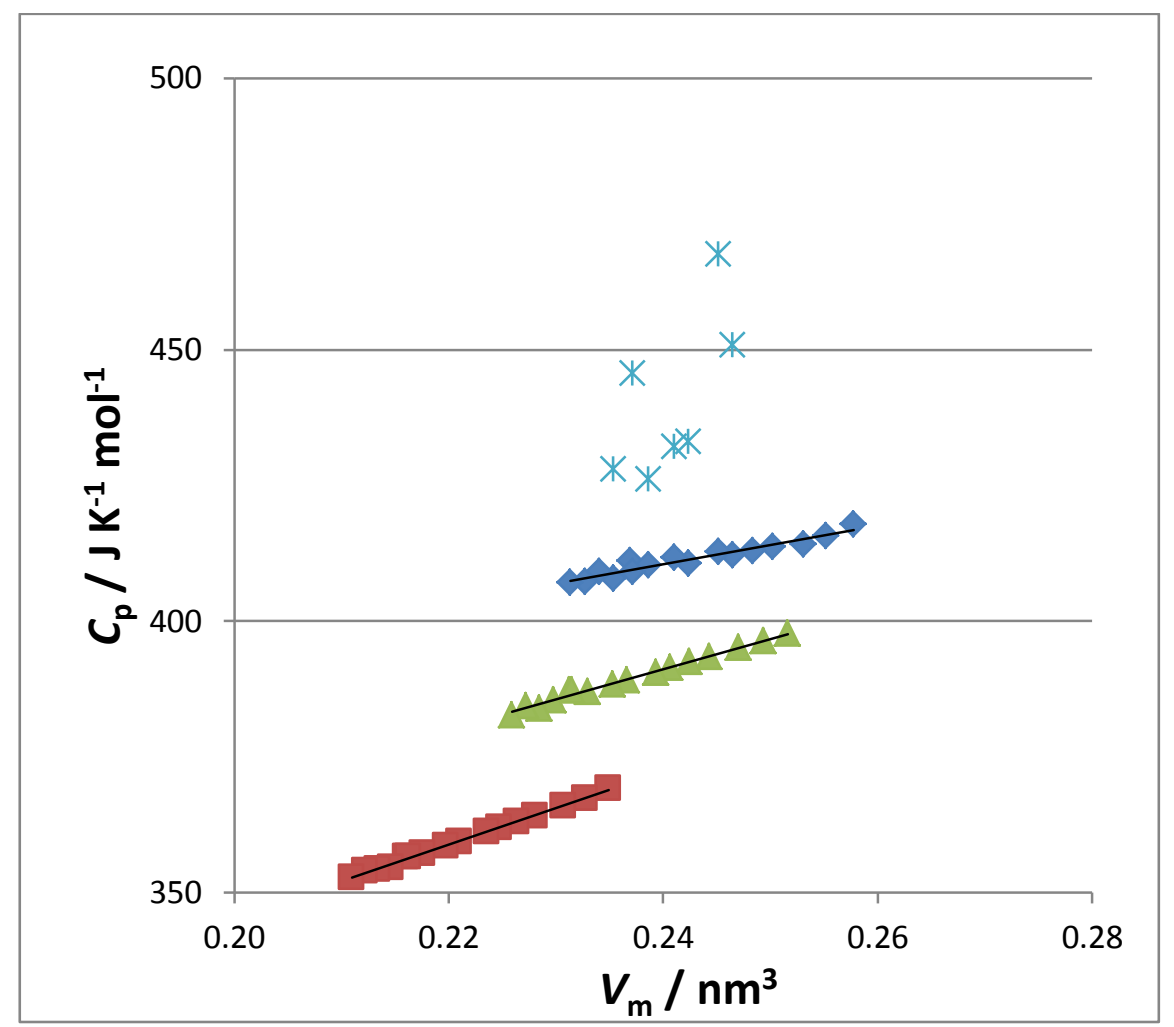

Fig. 3: Ambient heat capacity versus molecular formula volume. Red squares: $\mathrm{Ln}_{3} \mathrm{Al}_{5} \mathrm{O}_{12}$; blue diamonds: $\mathrm{Ln}_{3} \mathrm{Fe}_{5} \mathrm{O}_{12}$; blue stars: $\mathrm{Ln}_{3} \mathrm{Fe}_{5} \mathrm{O}_{12}$ ex Parida, et al. [9]; green triangles: $\mathrm{Ln}_{3} \mathrm{Ga}_{5} \mathrm{O}_{12}$. Data in Table 1.

In Fig. 4, we see a very rough general tendency of absolute entropy to increase with formula volume [13], in a general similarity with the observations in Fig. 3, with rising and falling magnetic contributions (Table $11[8]$ ) occasioning the pairs of generally convex curves. However, we now note a number of anomalies, as may also be seen in Fig. S1c; in particular, the entropies of the Eu and end-member (La and Lu) lanthanoid garnets are low. It is also noticeable that the entropy of $\mathrm{Yb}_{2} \mathrm{Fe}_{3} \mathrm{O}_{12}$ (second blue diamond) is low compared with the values for its alumino- and gallo- homologues. The more voluminous of the ferrigarnets $(\mathrm{Eu} \rightarrow \mathrm{Lu})$ also seem to have anomalously low 
entropies compared with their ferrigarnet homologues. Again, the experimental values for the ferrigarnets reported by Parida, et al. [9] are some 10\% larger than the the fitted values of Moretti and Ottonello [8] and do not follow a clearly consistent pattern.

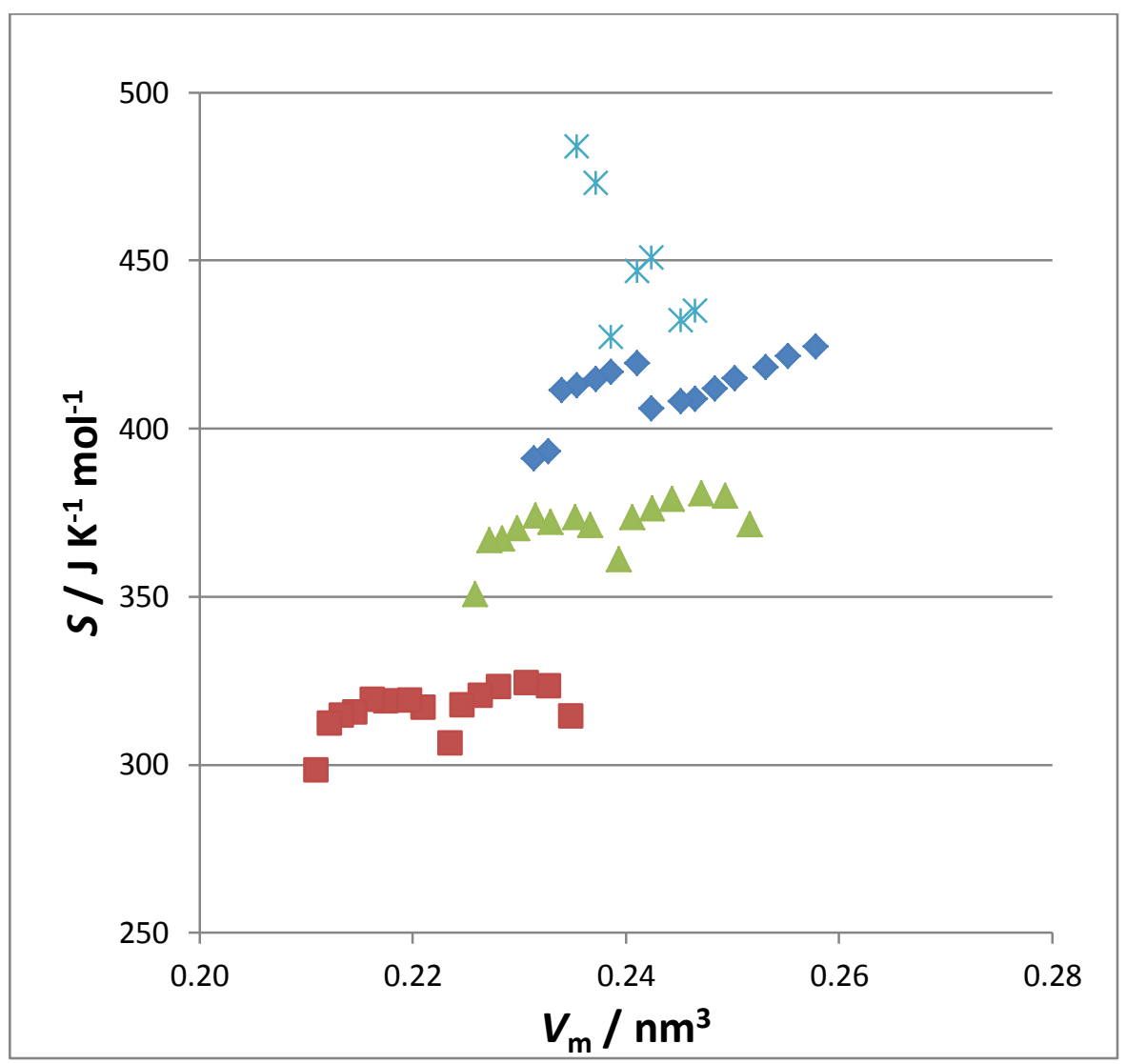

Fig. 4: Ambient absolute entropy versus molecular formula volume. Red squares: $\mathrm{Ln}_{3} \mathrm{Al}_{5} \mathrm{O}_{12}$; blue diamonds: $\mathrm{Ln}_{3} \mathrm{Fe}_{5} \mathrm{O}_{12}$; blue stars: $\mathrm{Ln}_{3} \mathrm{Fe}_{5} \mathrm{O}_{12}$ ex Parida, et al. [9]; green triangles: $\mathrm{Ln}_{3} \mathrm{Ga}_{5} \mathrm{O}_{12}$. Data in Table 1. The data points for the yttrium garnets are omitted.

Glasser has shown [3] that ambient values of heat capacities and entropies of ionic solids are roughly equal $\left(C_{\mathrm{p}} / S \cong 1\right)$; ratios which are greater than 1 imply elevated Debye temperatures, $\Theta_{\mathrm{D}}$, reaching towards $600 \mathrm{~K}$ for ambient temperature data of $300 \mathrm{~K}$. We 
test this observation in Fig. 5 which plots the ratio, $C_{\mathrm{p}} / S$, of ambient heat capacity to entropy against formula volume for the lanthanoid garnets. When heat capacity and entropy are equal (at $433 \mathrm{~J} \mathrm{~K}^{-1} \mathrm{~mol}^{-1}$ for the 20 -atom lanthanoid garnets in the Debye analysis), $T / \Theta_{\mathrm{D}}=0.58(6)$; thus $\Theta_{\mathrm{D}}$ is about $500 \mathrm{~K}$ for such materials. It is notable that the ratios of the data for ferrigarnets from Parida, et al. [9] fit broadly into this general pattern, but with considerable discrepancies for $\mathrm{Er}_{3} \mathrm{Fe}_{5} \mathrm{O}_{12}\left(C_{\mathrm{p}} / S=0.88\right)$ and $\mathrm{Eu}_{3} \mathrm{Fe}_{5} \mathrm{O}_{12}$ $\left(C_{\mathrm{p}} / S=1.08\right)$. Parida, et al., do not provide estimates of the accuracy of their values of heat capacity or entropy.

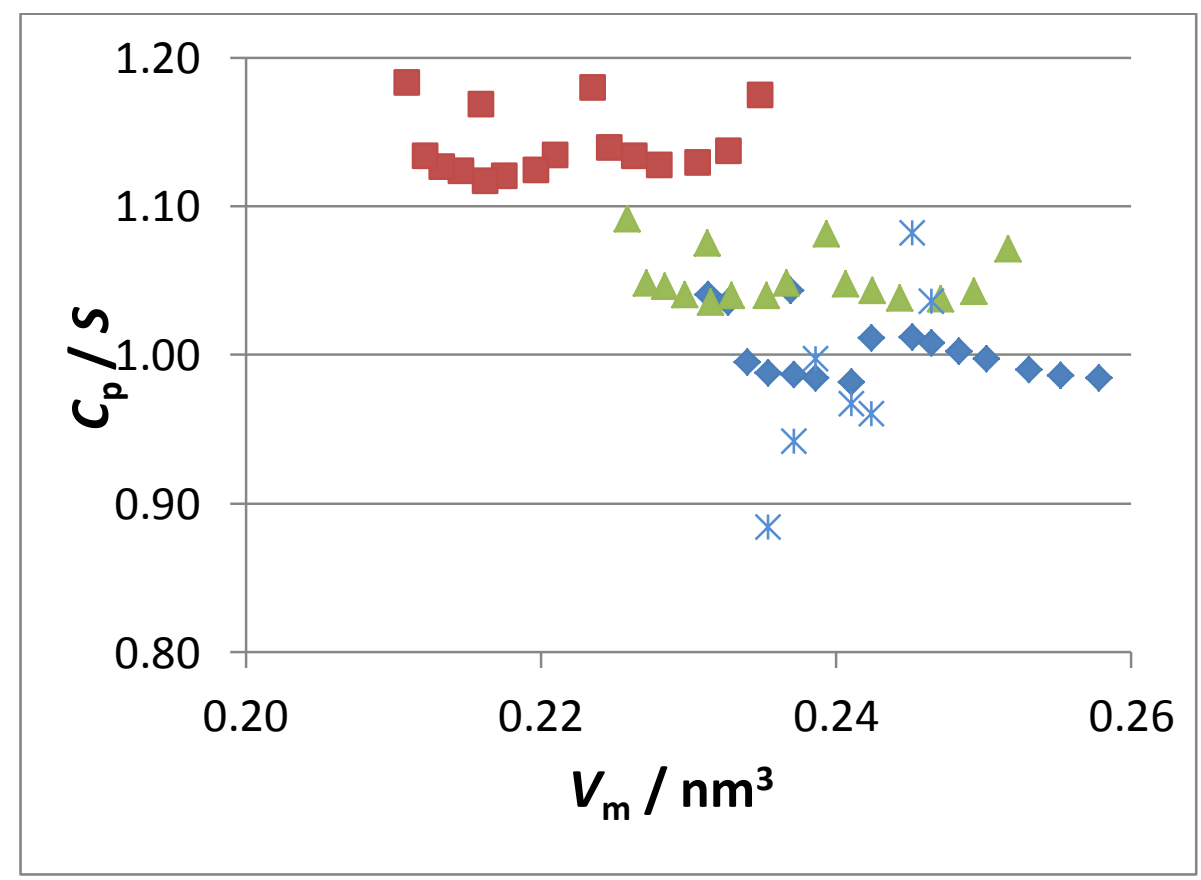

Fig. 5: Ratio, $C_{\mathrm{p}} / S$, of ambient heat capacity to absolute entropy against formula volume. Red squares: $\mathrm{Ln}_{3} \mathrm{Al}_{5} \mathrm{O}_{12}$; blue diamonds: $\mathrm{Ln}_{3} \mathrm{Fe}_{5} \mathrm{O}_{12}$; blue stars: $\mathrm{Ln}_{3} \mathrm{Fe}_{5} \mathrm{O}_{12}$ ex Parida, et al. [9]; green triangles: $\mathrm{Ln}_{3} \mathrm{Ga}_{5} \mathrm{O}_{12}$. Data in Table 1 . The data points for the yttrium garnets are omitted. 
In Fig. 6, we see that that the compressibilities of the lanthanoid garnets are closely proportional to their formula volumes $[14 ; 15]$. The slope of the plot corresponds well with data for perovskites, $\mathrm{ABO}_{3}$, with a slope of $0.276 \mathrm{GPa}^{-1}$ per $\mathrm{nm}^{3}$ of ion pair - the correspondence of the garnet formula with a perovskite oxide is noted in the relation $\mathrm{M}_{3} \mathrm{X}_{5} \mathrm{O}_{12} \cong 4 \mathrm{M}_{2} \mathrm{O}_{3}$

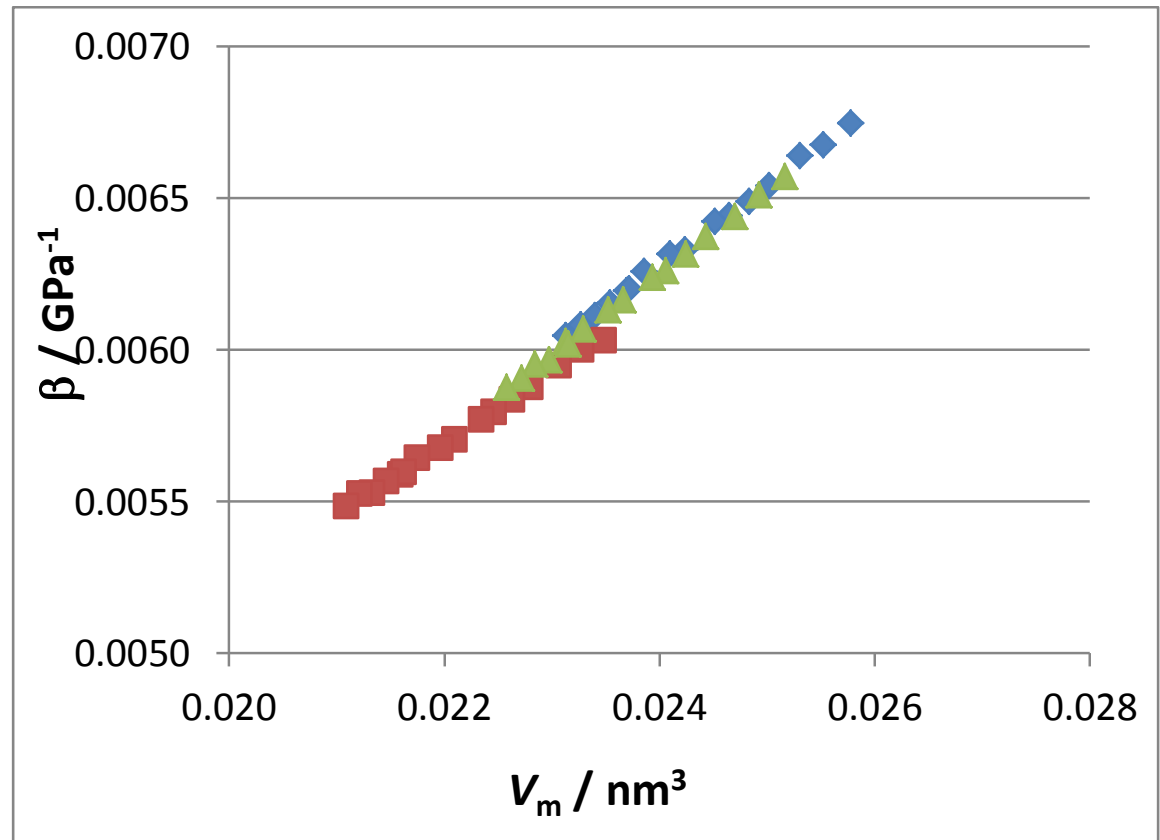

Fig. 6: Isothermal compressibility, $\beta / \mathrm{GPa}^{-1}$, of lanthanoid garnets plotted against molecular formula volume. Red squares: $\mathrm{Ln}_{3} \mathrm{Al}_{5} \mathrm{O}_{12}$; blue diamonds: $\mathrm{Ln}_{3} \mathrm{Fe}_{5} \mathrm{O}_{12}$; green triangles: $\mathrm{Ln}_{3} \mathrm{Ga}_{5} \mathrm{O}_{12}$. Data points for the yttrium garnets are included in this plot. (Significant gaps in formula volumes may be seen between $\mathrm{Eu}$ and $\mathrm{Gd}$ and between $\mathrm{Tb}$ and Dy garnets, as may also be seen on inspection of the earlier Figures.) The overall fitted least squares line (not shown) has a slope of $0.278 \mathrm{GPa}^{-1}$ per $\mathrm{nm}^{3}\left(\mathrm{R}^{2}=0.994\right)$. 
The abscissa values of lattice energies, $U_{\mathrm{POT}}$, in Fig. 7 are calculated with an established "limiting equation" which applies strictly to larger volume ionic materials [16] such as the lanthanoid garnets, namely:

$$
U_{\mathrm{POT}}=A I\left(2 I / V_{m}\right)^{1 / 3}
$$

where the electrostatic constant, $A=121.4 \mathrm{~kJ} \mathrm{~mol}^{-1} \mathrm{~nm}$; and ionic strength factor, $I=1 / 2 \sum_{i}^{t} n_{i} z_{i}^{2}$ where $n_{\mathrm{i}}$ is the number of ionic species of integer charge $z_{\mathrm{i}}$ in the formula unit. This equation is dependent on only the ion charges and formula volume, independent of any other considerations. In the final columns of Table 2, we list values of the lattice energy according to this "limiting equation". The plot shows that the "limiting equation" provides an adequate representation of the lattice energy (between $-1.8 \pm 0.3 \%$ for gallogarnets, $-2.9 \pm 0.3 \%$ for aluminogarnets, and $-4.7 \pm 0.2 \%$ for ferrigarnets). The observation that the aluminogarnets have the most negative lattice energies suggests that they are the most ionic of the set, with more covalency obtruding in the ferri- and gallogarnets. 


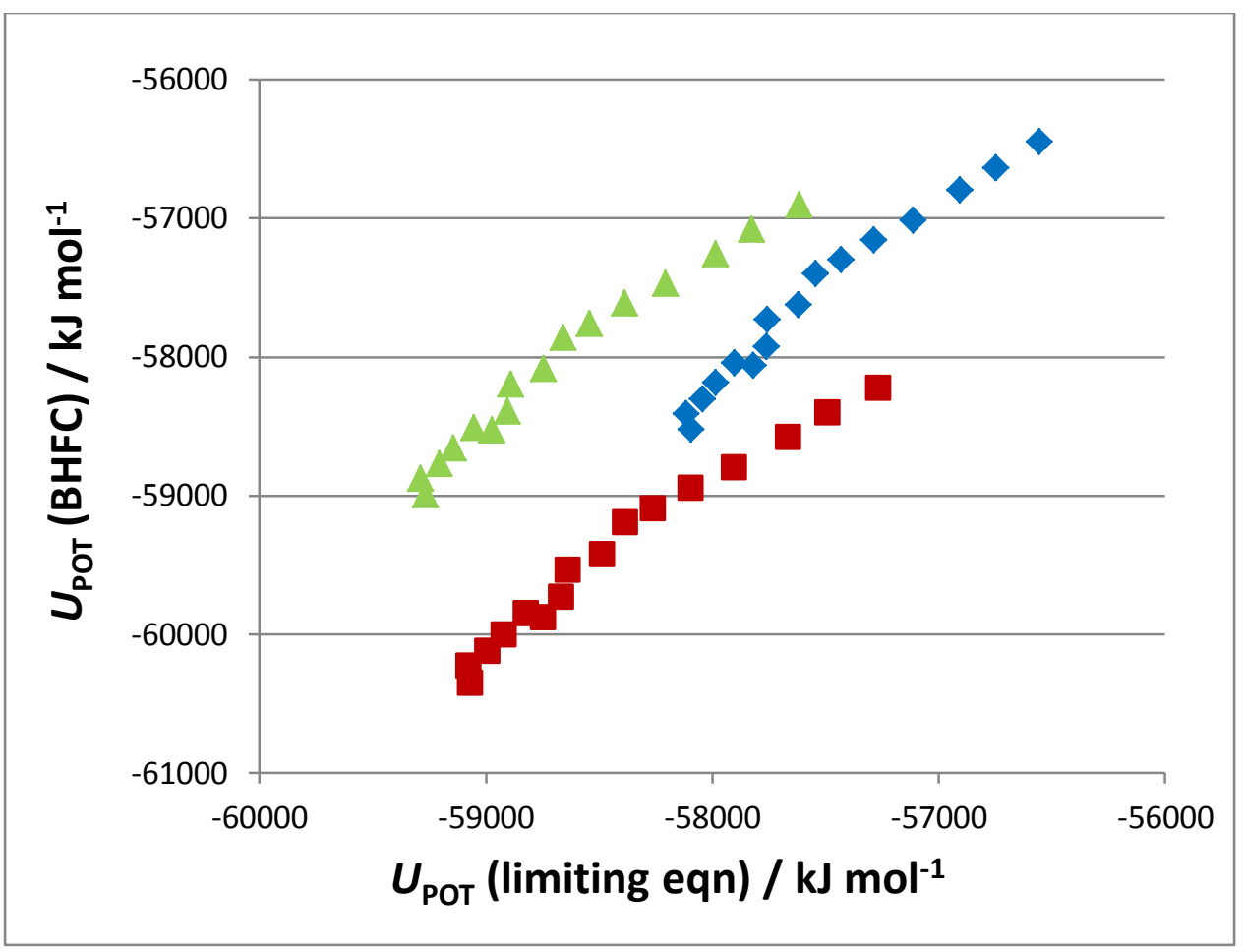

Fig. 7: Plot of lattice energy (calculated in a Born-Haber-Fajans thermochemical cycle using published formation enthalpies) against the purely electrostatic "limiting equation" (see text). Red squares: $\mathrm{Ln}_{3} \mathrm{Al}_{5} \mathrm{O}_{12}$; blue diamonds: $\mathrm{Ln}_{3} \mathrm{Fe}_{5} \mathrm{O}_{12}$; green triangles:

$\mathrm{Ln}_{3} \mathrm{Ga}_{5} \mathrm{O}_{12}$.

The ratios $U_{\text {latt }} / E_{\mathrm{pot}}$ (where $E_{\mathrm{pot}}$ is the Madelung or electrostatic energy [17]) of the data in Fig. 8 are $0.852 \pm 0.001$ for the ferrigarnets, $0.862 \pm 0.002$ for the gallogarnets, and 0.834 \pm 0.001 for the aluminogarnets. These results are rather smaller than the value of 0.963 earlier observed for a diverse set of ionic materials [17], suggesting the presence of some covalency. A further significant observation is that the largest electrostatic energy (and so smallest energy ratio) applies to the aluminogarnets - this implies that they have the largest ionic contribution, with the ferri- and gallo-garnets exhibiting somewhat greater covalency, confirming the observation noted for Fig. 7. 


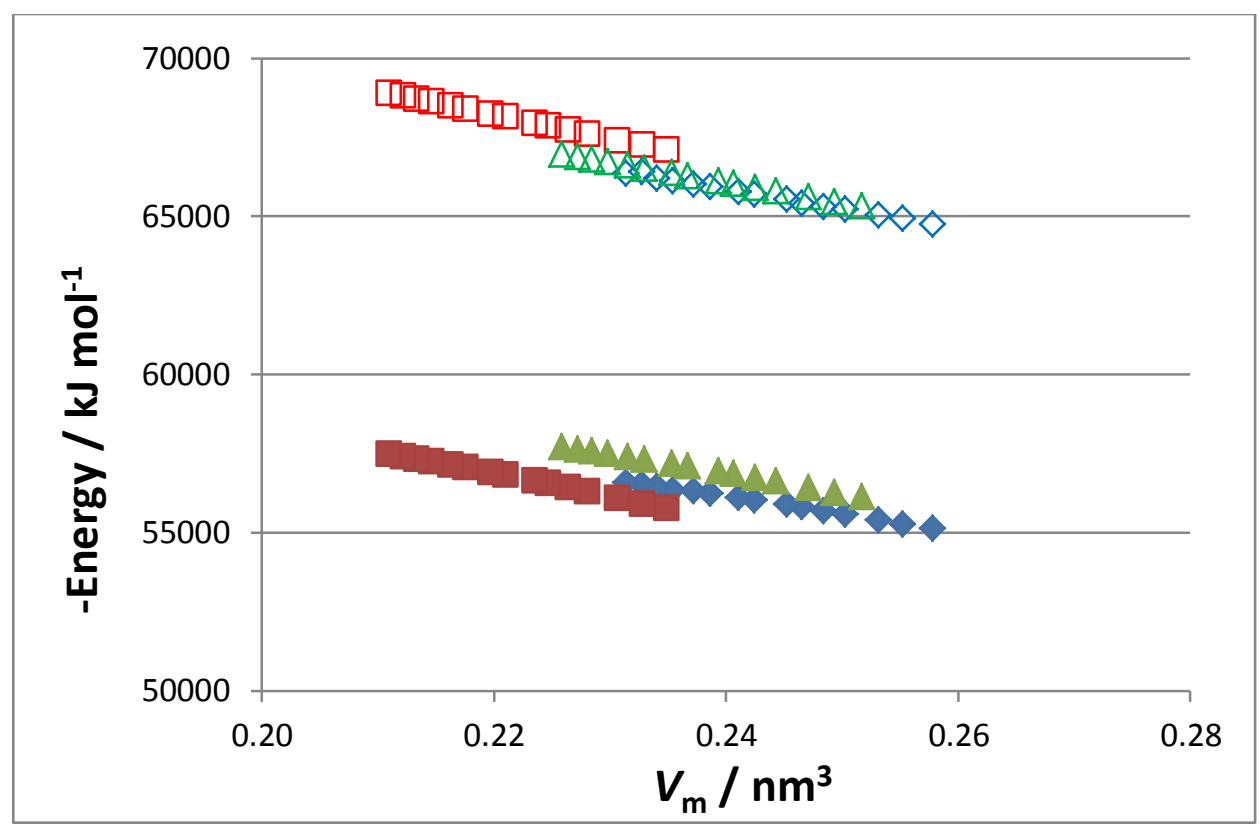

Fig. 8: Madelung (electrostatic) energy, $E_{\mathrm{POT}}$ (open symbols), and lattice energy, $U_{\text {latt }}$ (filled symbols) $/ \mathrm{kJ} \mathrm{mol}^{-1}$ (note reversal of sign) plotted versus molecular formula volume / $\mathrm{nm}^{3}$. Red squares: $\mathrm{Ln}_{3} \mathrm{Al}_{5} \mathrm{O}_{12}$; blue diamonds: $\mathrm{Ln}_{3} \mathrm{Fe}_{5} \mathrm{O}_{12}$; green triangles: $\mathrm{Ln}_{3} \mathrm{Ga}_{5} \mathrm{O}_{12}$.

From Kanke and Navrotsky [18] we have an independent set of formation enthalpies and entropies for the ferrigarnets from oxide synthesis, which may be compared with the data of Moretti and Ottonello [8]. In Table 3, we convert the published oxide synthesis results to standard elemental values, using current oxide values in the HSC database [19], and compare the results to those of Moretti and Ottonello. The formation enthalpies are in excellent agreement to within about $1.5 \%$. It is observed that the formation enthalpies obtained by Moretti and Ottonello [8] and by our "limiting" lattice-energy equation [16] are also in excellent agreement. However, there are serious discrepancies among the values for ambient absolute entropies. 
Table 2: Comparison of formation enthalpies $\left(/ \mathrm{kJ} \mathrm{mol}^{-1}\right)$ and absolute entropies $\left(/ \mathrm{J} \mathrm{K}^{-1}\right.$ $\mathrm{mol}^{-1}$ ) of lanthanoid ferrigarnets, as determined via oxide synthesis (columns 5) converted to elemental basis using reference data from the HSC [19] database (columns 6), and those listed by Moretti and Ottonello (M\&O) [8]. Percent differences from columns 6 are listed in columns 8 .

\begin{tabular}{|c|c|c|c|c|c|c|c|c|c|c|c|}
\hline 1 & 2 & 3 & 4 & \multicolumn{2}{|c|}{5} & 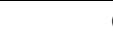 & & \multicolumn{2}{|c|}{7} & \multicolumn{2}{|c|}{8} \\
\hline \multirow[t]{2}{*}{ Oxide } & \multirow{2}{*}{ 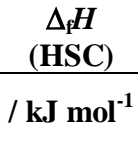 } & \multirow{2}{*}{$\begin{array}{c}\begin{array}{c}S \\
(\mathbf{H S C})\end{array} \\
\mathrm{J} \mathrm{K}^{-1} \\
\mathbf{m o l}^{-1}\end{array}$} & \multirow[t]{2}{*}{ Ferrigarnet } & \multicolumn{2}{|c|}{ from Oxides } & \multicolumn{4}{|c|}{ from Elements } & \multirow{2}{*}{\multicolumn{2}{|c|}{$\begin{array}{c}\text { \% diff from } \\
\text { HSC } \\
\text { from M\&O }\end{array}$}} \\
\hline & & & & & & \multicolumn{2}{|c|}{ HSC } & \multicolumn{2}{|c|}{ M\&O } & & \\
\hline $\mathrm{Fe}_{2} \mathrm{O}_{3}$ & -823.41 & 87.47 & & $\Delta_{\mathrm{f}} H$ & $\Delta_{\mathrm{f}} S$ & $\Delta_{\mathrm{f}} H$ & $S$ & $\Delta_{\mathrm{f}} H$ & $S$ & $\Delta_{\mathrm{f}} H$ & $S$ \\
\hline $\mathrm{Sm}_{2} \mathrm{O}_{3}$ & -1827.1 & 146.0 & $\mathrm{Sm}_{3} \mathrm{Fe}_{5} \mathrm{O}_{12}$ & -238.49 & -24.20 & -5050.9 & 413.3 & -4997.3 & 408.8 & 1.1 & -1.1 \\
\hline $\mathrm{Eu}_{2} \mathrm{O}_{3}$ & -1657.9 & 138.0 & $\mathrm{Eu}_{3} \mathrm{Fe}_{5} \mathrm{O}_{12}$ & -238.49 & -28.38 & -4797.1 & 397.1 & -4720.1 & 408.0 & 1.6 & 2.7 \\
\hline $\mathrm{Gd}_{2} \mathrm{O}_{3}$ & -1839.5 & 152.3 & $\mathrm{Gd}_{3} \mathrm{Fe}_{5} \mathrm{O}_{12}$ & -234.30 & -28.38 & -5065.3 & 418.6 & -4994.3 & 405.9 & 1.4 & -3.1 \\
\hline $\mathrm{Tb}_{2} \mathrm{O}_{3}$ & -1865.2 & 160.0 & $\mathrm{~Tb}_{3} \mathrm{Fe}_{5} \mathrm{O}_{12}$ & -209.20 & -15.83 & -5078.8 & 442.7 & -5030.2 & 419.3 & 1.0 & -5.6 \\
\hline $\mathrm{Dy}_{2} \mathrm{O}_{3}$ & -1862.7 & 150.6 & $\mathrm{Dy}_{3} \mathrm{Fe}_{5} \mathrm{O}_{12}$ & -184.10 & -3.28 & -5049.9 & 441.2 & -5012.1 & 416.7 & 0.8 & -5.9 \\
\hline $\mathrm{Ho}_{2} \mathrm{O}_{3}$ & -1881.1 & 158.7 & $\mathrm{Ho}_{3} \mathrm{Fe}_{5} \mathrm{O}_{12}$ & -133.89 & 26.01 & -5027.3 & 482.5 & -5038.3 & 414.7 & -0.2 & -16.4 \\
\hline $\mathrm{Er}_{2} \mathrm{O}_{3}$ & -1897.9 & 154.3 & $\mathrm{Er}_{3} \mathrm{Fe}_{5} \mathrm{O}_{12}$ & -83.68 & 55.30 & -5002.3 & 505.3 & -5044.9 & 412.8 & -0.8 & -22.4 \\
\hline $\mathrm{Tm}_{2} \mathrm{O}_{3}$ & -1888.7 & 139.7 & $\mathrm{Tm}_{3} \mathrm{Fe}_{5} \mathrm{O}_{12}$ & -58.58 & 59.48 & -4963.3 & 487.6 & -5016.3 & 411.3 & -1.1 & -18.6 \\
\hline $\mathrm{Y}_{2} \mathrm{O}_{3}$ & -1905.0 & 99.2 & $\mathrm{Y}_{3} \mathrm{Fe}_{5} \mathrm{O}_{12}$ & -75.31 & 46.93 & -5004.6 & 414.2 & -5085.9 & 394.0 & -1.6 & -5.1 \\
\hline $\mathrm{Lu}_{2} \mathrm{O}_{3}$ & -1878.2 & 110.0 & $\mathrm{Lu}_{3} \mathrm{Fe}_{5} \mathrm{O}_{12}$ & -8.37 & 80.40 & -4897.4 & 463.8 & -4967.7 & 391.1 & -1.4 & -18.6 \\
\hline
\end{tabular}

\section{Additive Single-ion Values}

We have developed additive single-ion values for the lanthanoid garnets from the data of Moretti and Ottonello [8] for volume, heat capacity, entropy, formation enthalpy and compressibility, and these are listed in Table 3. The values have been determined by non-linear optimization (using the Microsoft Excel "Solver" routine) of the single-ion values, where the sums generated are compared with the literature values for the corresponding thermodynamic property, and the sum-of-squares of the differences minimised. Since such optimizations do not necessarily yield a global minimum, but tend 
to fall into local minima of similar magnitude, it is appropriate to provide a fixed reference value for one of the ions in each case. Reference values for the $\mathrm{La}^{3+}$ ion are readily available, and so these values were fixed in an initial optimization. These values were then freed, and the optimization repeated, without significant shifts in the results, showing that a true local minimum had been obtained in the optimization.

The Table shows that the volumes obtained for the lanthanide cations are very similar to those of the independently-determined set of Glasser and Jenkins [20], confirming that these volumes may be reliably used in volume estimation for other materials. 
Table 3: Additive single-ion values for the lanthanoid garnets. The values for the $\mathrm{La}^{3+}$ ion were initially fixed at literature values (except for volume, $V$, which is based on $\mathrm{Dy}^{3+}$ ), then freed in a subsequent optimization [20] without a resultant shifting in values. Values for the $\mathrm{Pm}^{3+}$ ion are linear interpolations of the neighbouring data values.

\begin{tabular}{|c|r|r|r|r|r|r|}
\hline & $\begin{array}{c}\boldsymbol{V} \\
/ \mathrm{nm}^{3}\end{array}$ & \multicolumn{1}{c|}{$\begin{array}{r}\boldsymbol{V}^{\mathrm{a}} \\
/ \mathrm{nm}^{3}\end{array}$} & $\begin{array}{c}\boldsymbol{C}_{\mathrm{p}} \\
/ \mathrm{J} \mathrm{K}^{-1} \mathrm{~mol}^{-1}\end{array}$ & $\begin{array}{c}\boldsymbol{S} \\
/ \mathrm{J} \mathrm{K}^{-1} \mathrm{~mol}^{-1}\end{array}$ & $\begin{array}{c}\mathbf{\Delta}_{\mathrm{f}} \mathbf{H} \\
/ \mathrm{kJ} \mathrm{mol}^{-1}\end{array}$ & $\begin{array}{c}\boldsymbol{\beta} \\
/ \mathrm{GPa}^{-1}\end{array}$ \\
\hline $\mathrm{O}_{12}{ }^{12-}$ & 0.135 & & 15.6 & 3.3 & -2143 & -0.00022 \\
\hline $\mathrm{Fe}_{5}{ }^{15+}$ & 0.063 & & 317.6 & 325.9 & -132 & 0.00059 \\
\hline $\mathrm{Al}_{5}{ }^{15+}$ & 0.041 & & 266.0 & 230.2 & -2142 & 0.00027 \\
\hline $\mathrm{Ga}_{5}{ }^{15+}$ & 0.057 & & 295.7 & 285.1 & -739 & 0.00051 \\
\hline $\mathrm{Y}^{3+}$ & 0.013 & 0.0131 & 25.4 & 23.1 & -947 & 0.00091 \\
\hline & & & & & & \\
\hline $\mathrm{La}^{3+}$ & 0.020 & & $28.8^{\mathrm{a}}$ & $28.8^{\mathrm{a}, \mathrm{b}}$ & $-786^{\mathrm{C}}$ & 0.00099 \\
\hline $\mathrm{Ce}^{3+}$ & 0.019 & & 28.2 & 30.4 & -790 & 0.00099 \\
\hline $\mathrm{Pr}^{3+}$ & 0.018 & & 27.7 & 30.2 & -810 & 0.00097 \\
\hline $\mathrm{Nd}^{3+}$ & 0.017 & & 27.3 & 29.5 & -840 & 0.00096 \\
\hline $\mathrm{Pm}^{3+}$ & 0.017 & & 27.0 & 28.6 & -871 & 0.00095 \\
\hline $\mathrm{Sm}^{3+}$ & 0.016 & 0.0164 & 26.6 & 27.6 & -902 & 0.00095 \\
\hline $\mathrm{Eu}^{3+}$ & 0.016 & 0.0146 & 26.5 & 24.9 & -811 & 0.00094 \\
\hline $\mathrm{Gd}^{3+}$ & 0.015 & 0.0133 & 25.9 & 27.0 & -907 & 0.00093 \\
\hline $\mathrm{Tb}^{3+}$ & 0.014 & 0.0148 & 25.9 & 29.0 & -921 & 0.00093 \\
\hline $\mathrm{Dy}^{3+}$ & 0.014 & 0.0137 & 25.4 & 28.5 & -919 & 0.00092 \\
\hline $\mathrm{Ho}^{3+}$ & 0.013 & & 25.2 & 28.5 & -930 & 0.00091 \\
\hline $\mathrm{Er}^{3+}$ & 0.013 & 0.0126 & 24.7 & 27.5 & -935 & 0.00091 \\
\hline $\mathrm{Tm}^{3+}$ & 0.012 & 0.0110 & 24.6 & 26.9 & -927 & 0.00090 \\
\hline $\mathrm{Yb}^{3+}$ & 0.012 & 0.0111 & 24.4 & 26.1 & -884 & 0.00089 \\
\hline $\mathrm{Lu}^{3+}$ & 0.011 & 0.0102 & 24.1 & 21.0 & -915 & 0.00089 \\
\hline
\end{tabular}

${ }^{\text {a }}$ Reference [20].

${ }^{\mathrm{b}}$ Since ambient heat capacity and entropy are approximately equal [3], the heat capacity value for $\mathrm{La}^{3+}$ has also been used as reference value for its entropy.

${ }^{\mathrm{c}}$ Reference [21].

${ }^{\mathrm{d}}$ Reference [22]. 


\section{Conclusion}

We have examined systematic thermodynamic relations among the lanthanoid garnets. Most of these thermodynamic properties show smooth correlations; however, the europium and ytterbium lanthanoid garnets show some anomalies, which are explicable for the Eu materials in terms of the absence of a magnetic spin entropy for the $\mathrm{Eu}^{3+}$ ion, while thermodynamic anomalies between $\mathrm{Yb}$ and $\mathrm{Lu}$ garnets appear to arise from the shielding effects of a complete electron shell for $\mathrm{Lu}^{3+}$.

We have developed additive single-ion properties (ion volume, heat capacity, entropy, formation enthalpy and compressibility) for the trivalent lanthanide cations which may be useful in the estimation of thermodynamic properties of lanthanoid materials. 


\section{Supplementary Information}

Supplementary Figures S1a to S1f for the lanthanoid garnets represent data for formula volume, isochoric heat capacity, absolute entropy, formation enthalpy, lattice energy, and isothermal compressibility, respectively, while Supplementary Figures S2a to S2f represent additive single-ion values for the same properties.

\section{Acknowledgement}

Curtin University is thanked for its continued support of this work by provision of facilities and office space. 


\section{References}

[1] L. Glasser, J. Solid State Chem. 206 (2013) 139-144.

[2] S.W. Kieffer, Reviews of Geophysics 17 (1979) 35-59.

[3] L. Glasser, Inorg. Chem. 52 (2013) 6590-6594.

[4] L. Glasser, H.D.B. Jenkins, Chem. Soc. Rev. 34 (2005) 866-874.

[5] L. Glasser, H.D.B. Jenkins, J. Chem. Eng. Data 56 (2011) 874-880.

[6] L. Brewer, Systematics of the Properties of the Lanthanides. in: S.P. Sinha, (Ed.), Systematics and the Properties of the Lanthanides, D. Reidel Publ. Co., Dordrecht;

Boston; Lancaster, 1983, pp. 17-69.

[7] J.C. Duchesne, The Lanthanides as Geochemical Tracers of Igneous Processes: an Introduction. in: S.P. Sinha, (Ed.), Systematics and the Properties of the Lanthanides, D.

Reidel Publ. Co., Dordrecht; Boston; Lancaster, 1983, pp. 543-557.

[8] R. Moretti, G. Ottonello, Geochim. Cosmochim. Acta 62 (1998) 1147-1173.

[9] S. Parida, S. Rakshit, Z. Singh, J. Solid State Chem. 181 (2008) 101-121.

[10] D. Petrov, Thermochim. Acta 566 (2013) 414-315.

[11] H.D.B. Jenkins, L. Glasser, J. Chem. Eng. Data 55 (2010) 4231-4238.

[12] L. Glasser, H.D.B. Jenkins, Inorg. Chem. 50 (2011) 8565-8569.

[13] L. Glasser, H.D.B. Jenkins, Thermochim. Acta 414 (2004) 125-130.

[14] L. Glasser, Inorg. Chem. 49 (2010) 3424-3427.

[15] L. Glasser, J. Phys. Chem. C 114 (2010) 11248-11251.

[16] L. Glasser, H.D.B. Jenkins, J. Am. Chem. Soc. 122 (2000) 632-638.

[17] L. Glasser, Inorg. Chem. 51 (2012) 2420-2424.

[18] Y. Kanke, A. Navrotsky, J. Solid State Chem. 141 (1998) 424-436.

[19] Outotec Research Oy, HSC Chemistry 7 (2009).

[20] L. Glasser, H.D.B. Jenkins, Inorg. Chem. 51 (2012) 6360-6366.

[21] L. Glasser, Inorg. Chem. 52 (2013) 992-998.

[22] L. Glasser, H.D.B. Jenkins, Inorg. Chem. 47 (2008) 6195-6202. 


\section{Highlights}

- The thermodynamics of ferri-, alumino-, and gallo-lanthanoid garnets are examined.

- Europium and ytterbium/lutetium garnets exhibit some anomalies.

- Entropies from the literature are not well-established.

- Additive single-ion thermodynamic values are established for the trivalent lanthanide cations. 


\section{Graphical Abstract}

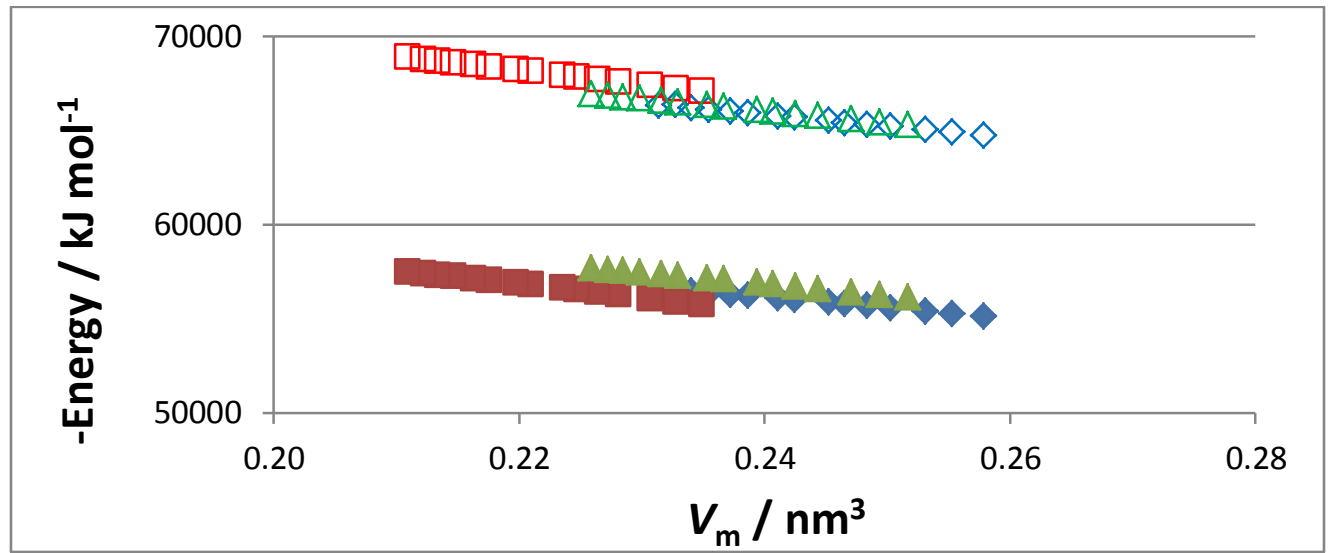

There exists much experimental data for lanthanoid garnets, which are strongly ionic

solids. We examine the consistencies among these structurally related materials and note some anomalous values, particularly for the europium and ytterbium garnets. 
Thermodynamic Consistencies and Anomalies

\title{
among Mineral and Lanthanoid End-member Garnets
}

\author{
Leslie Glasser* \\ Nanochemistry Research Institute, Department of Chemistry, \\ Curtin University, GPO Box U1987, Perth WA 6845, Australia
}

Supplementary Figures S1a-S1f, S2a-S2f

Keywords: Thermodynamics, solid state, ionic materials

${ }^{*}$ Corresponding author

L. Glasser: $\quad$ Telephone: + 618 9266-3126 Fax: + $6189266-4699$

E-mail: I.glasser@curtin.edu.au 


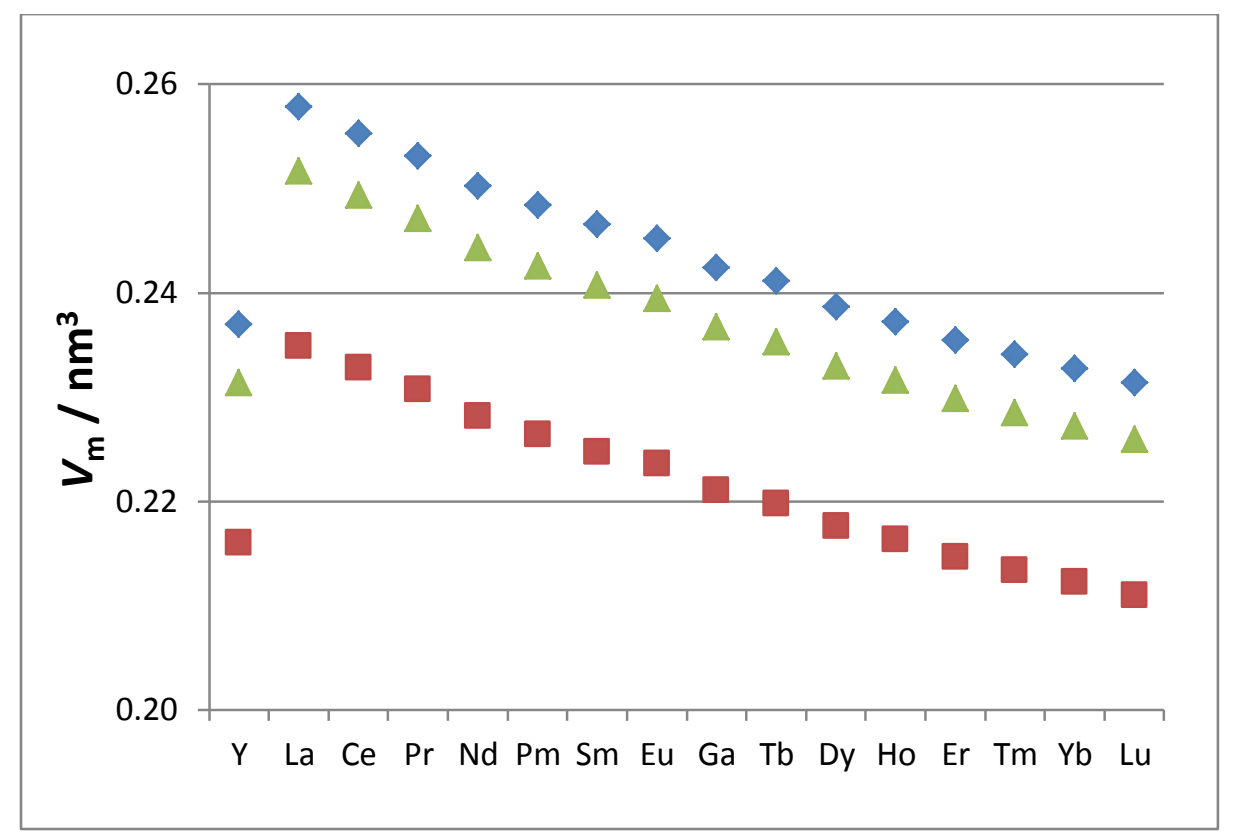

Figure S1a: Ambient formula volume, $V_{\mathrm{m}} / \mathrm{nm}^{3}$, of lanthanoid garnets plotted against atomic number. Red squares: $\mathrm{Ln}_{3} \mathrm{Al}_{5} \mathrm{O}_{12} ;$ blue diamonds: $\mathrm{Ln}_{3} \mathrm{Fe}_{5} \mathrm{O}_{12}$; green triangles: $\mathrm{Ln}_{3} \mathrm{Ga}_{5} \mathrm{O}_{12}$.

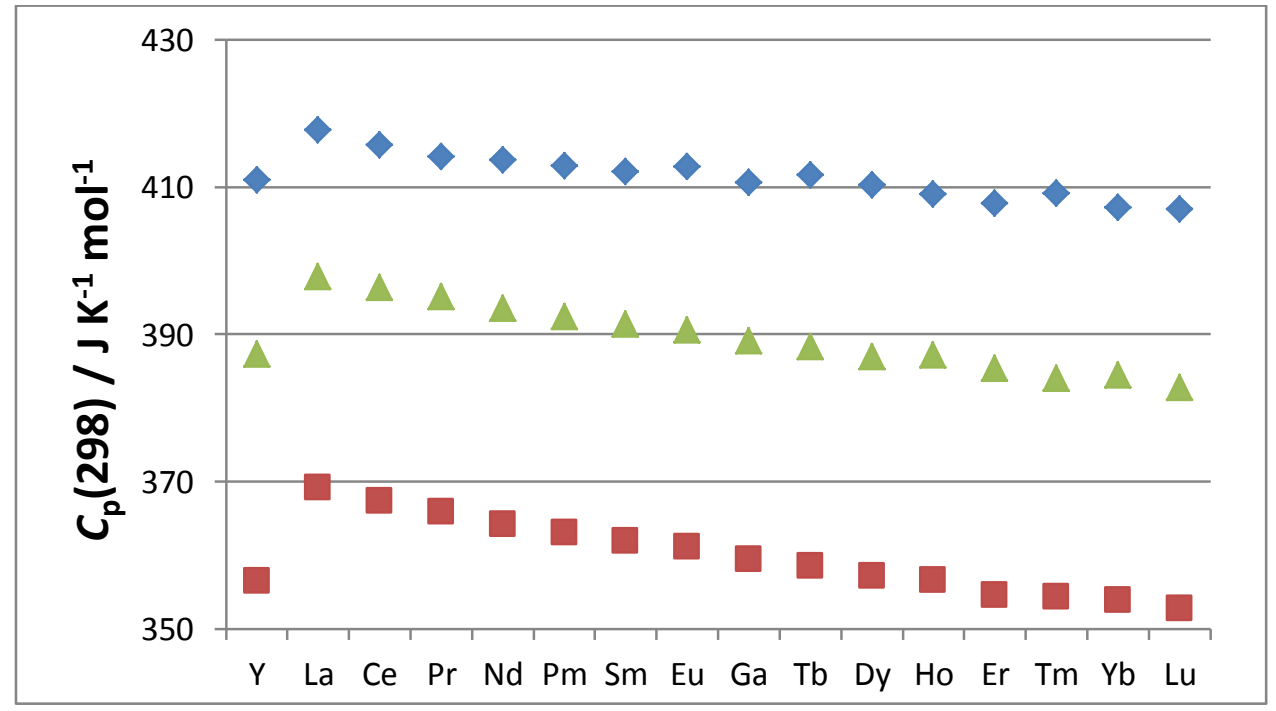

Figure S1b: Ambient isochoric heat capacity, $C_{\mathrm{p}} / \mathrm{J} \mathrm{K}^{-1} \mathrm{~mol}^{-1}$, of lanthanoid garnets plotted against atomic number. Red squares: $\mathrm{Ln}_{3} \mathrm{Al}_{5} \mathrm{O}_{12}$; blue diamonds: $\mathrm{Ln}_{3} \mathrm{Fe}_{5} \mathrm{O}_{12}$; green triangles: $\mathrm{Ln}_{3} \mathrm{Ga}_{5} \mathrm{O}_{12}$. 


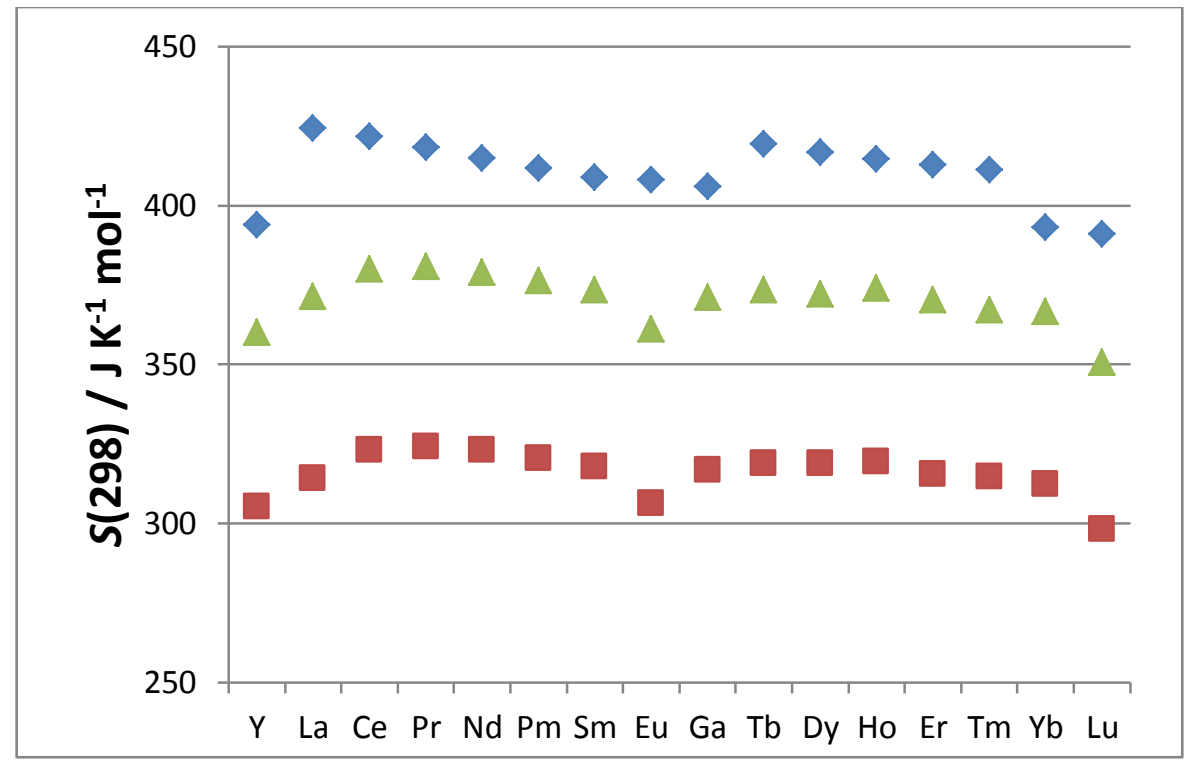

Figure S1c: Absolute ambient entropy, $\mathrm{S} / \mathrm{J} \mathrm{K}^{-1} \mathrm{~mol}^{-1}$, of lanthanoid garnets plotted against atomic number. Red squares: $\mathrm{Ln}_{3} \mathrm{Al}_{5} \mathrm{O}_{12}$; blue diamonds: $\mathrm{Ln}_{3} \mathrm{Fe}_{5} \mathrm{O}_{12}$; green triangles: $\mathrm{Ln}_{3} \mathrm{Ga}_{5} \mathrm{O}_{12}$.

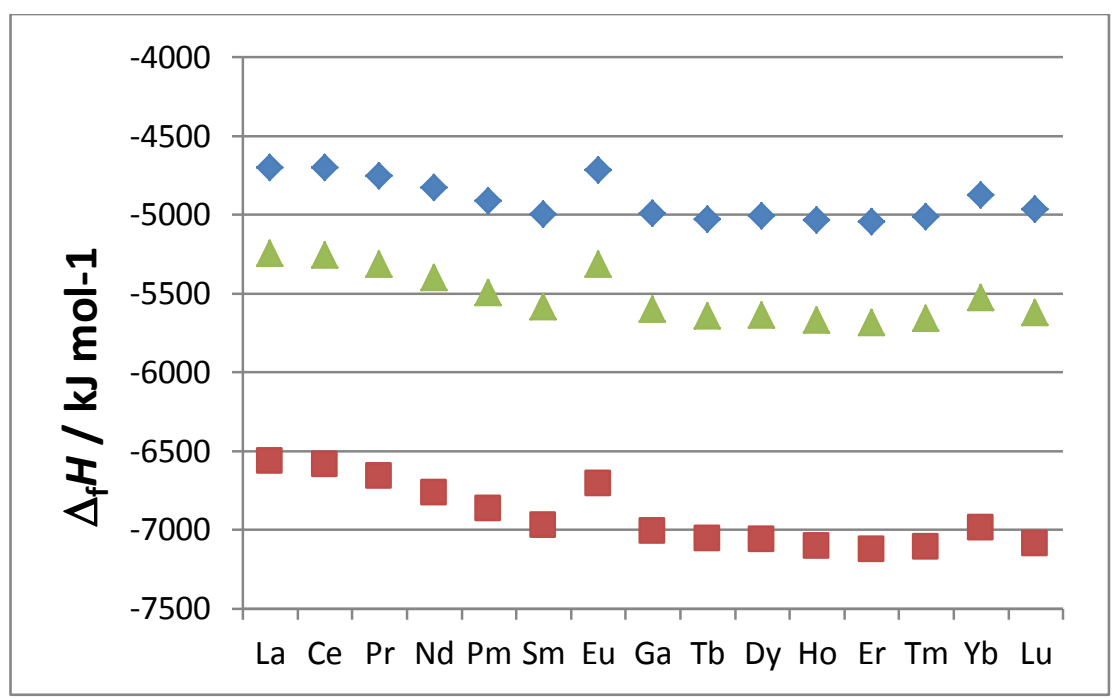

Figure S1d: Ambient formation enthalpy, $\Delta_{f} \mathrm{H} / \mathrm{J} \mathrm{K}^{-1} \mathrm{~mol}^{-1}$, of lanthanoid garnets plotted against atomic number. Red squares: $\operatorname{Ln}_{3} \mathrm{Al}_{5} \mathrm{O}_{12}$; blue diamonds: $\mathrm{Ln}_{3} \mathrm{Fe}_{5} \mathrm{O}_{12}$; green triangles: $\operatorname{Ln}_{3} \mathrm{Ga}_{5} \mathrm{O}_{12}$. 


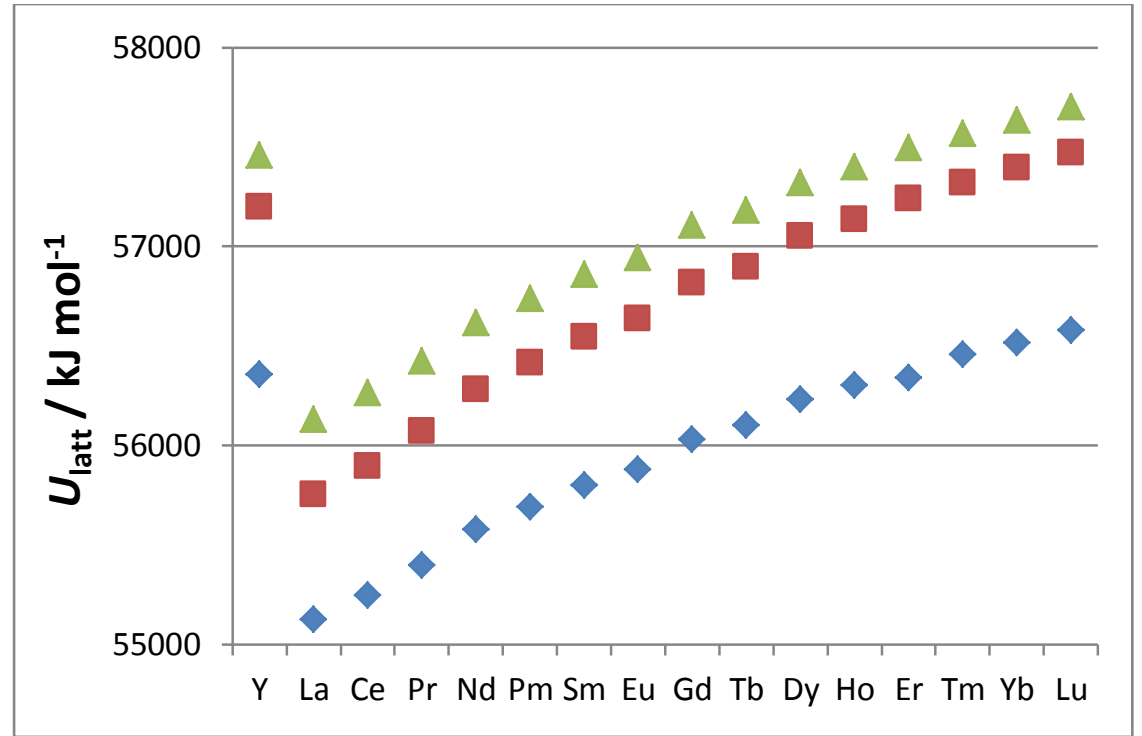

Figure S1e: Lattice energy, $U_{\text {latt }} / \mathrm{J} \mathrm{K}^{-1} \mathrm{~mol}^{-1}$, of lanthanoid garnets plotted against atomic number. Red squares: $\mathrm{Ln}_{3} \mathrm{Al}_{5} \mathrm{O}_{12} ;$ blue diamonds: $\mathrm{Ln}_{3} \mathrm{Fe}_{5} \mathrm{O}_{12}$; green triangles: $\mathrm{Ln}_{3} \mathrm{Ga}_{5} \mathrm{O}_{12}$.

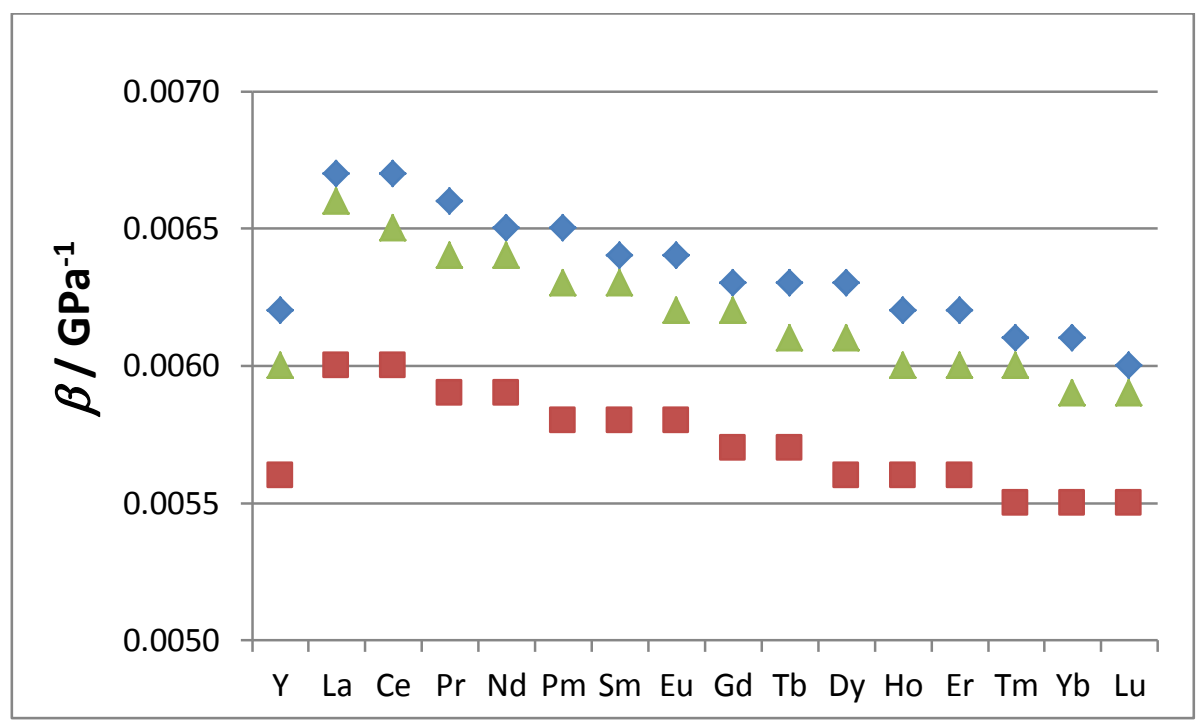

Figure S1f: Isothermal compressibility, $\beta / \mathrm{GPa}^{-1}$, of lanthanoid garnets plotted against atomic number. The steps in the data are due to the limited precision of the source data. Red squares: $\mathrm{Ln}_{3} \mathrm{Al}_{5} \mathrm{O}_{12} ;$ blue diamonds: $\mathrm{Ln}_{3} \mathrm{Fe}_{5} \mathrm{O}_{12}$; green triangles: $\mathrm{Ln}_{3} \mathrm{Ga}_{5} \mathrm{O}_{12}$. 


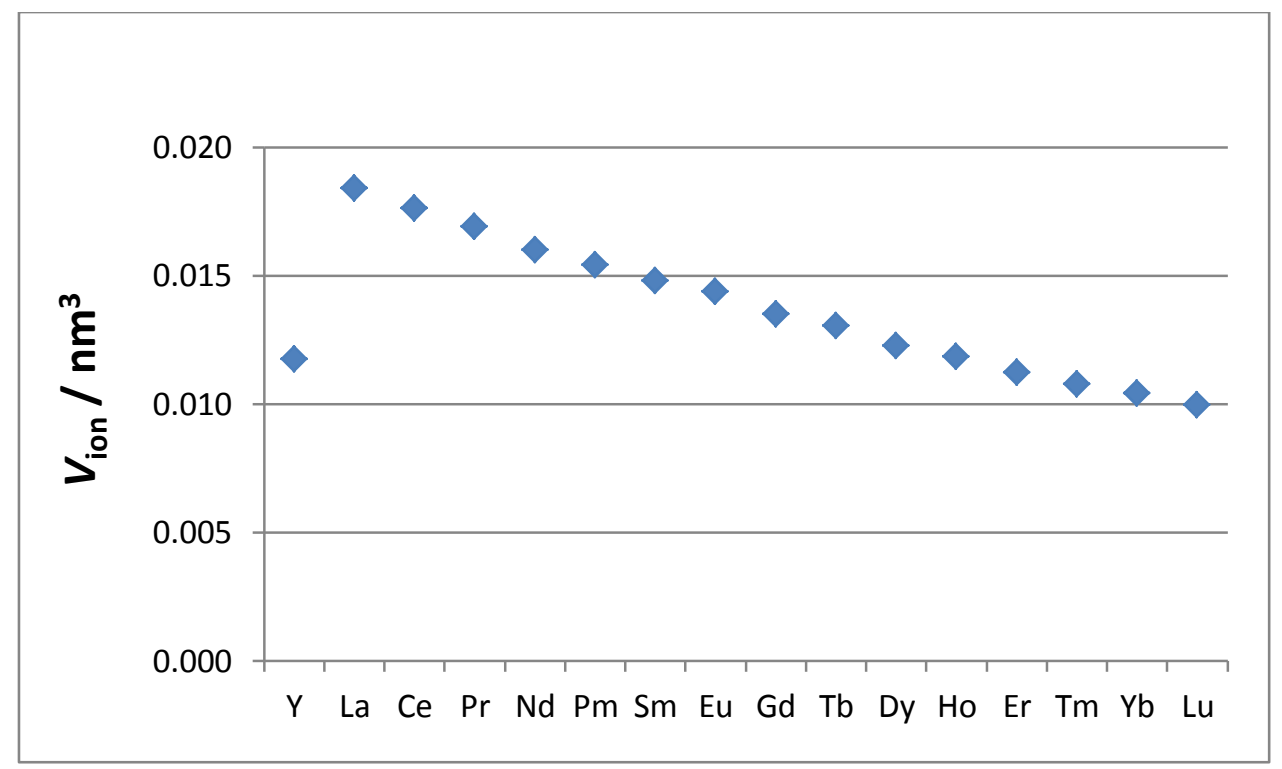

Figure S2a: Additive single-ion formula volume, $V_{\mathrm{m}} / \mathrm{nm}^{3}$, of lanthanoid garnets plotted against atomic number, with the $\mathrm{Dy}^{3+}$ ion value referred to an optimized self-consistent value [1].

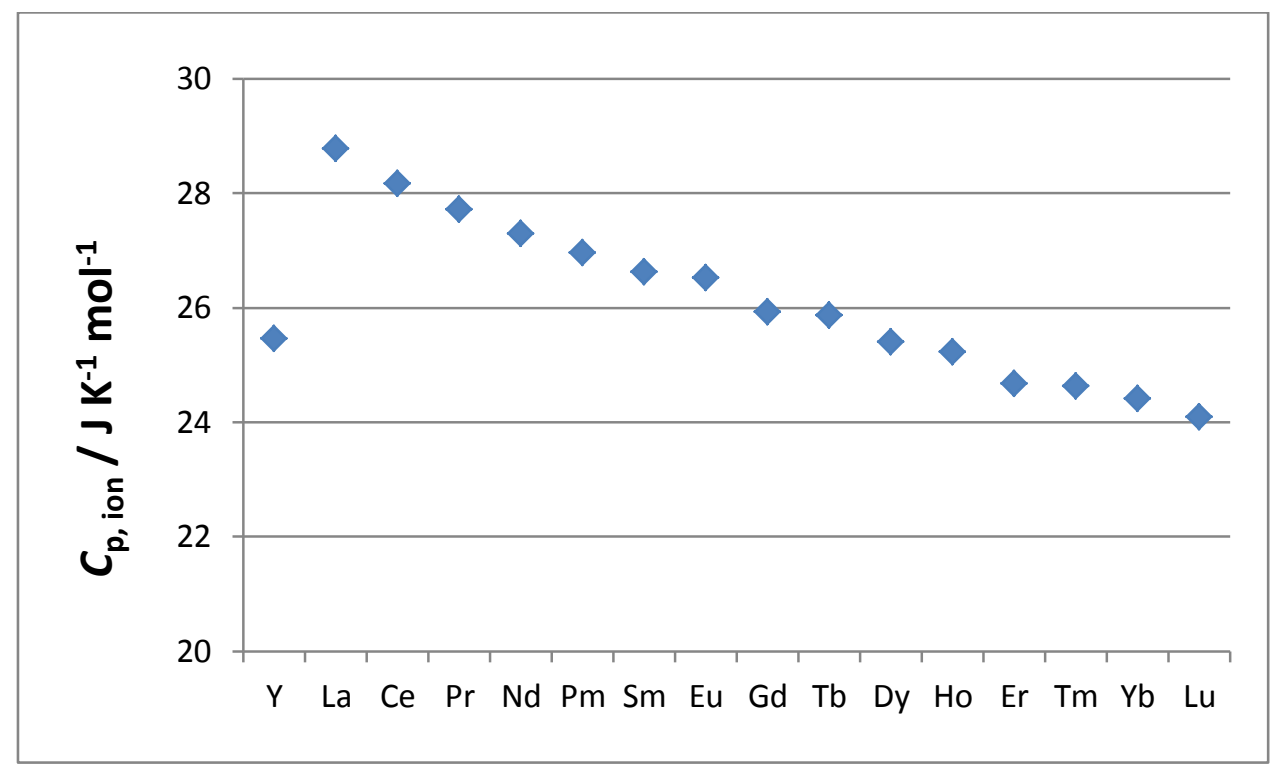

Figure S2b: Additive single-ion ambient isochoric heat capacity, $C_{\mathrm{p}} / \mathrm{J} \mathrm{K}^{-1} \mathrm{~mol}^{-1}$, of lanthanoid garnets plotted against atomic number, with the $\mathrm{La}^{3+}$ ion value referred to an optimized self-consistent value [2]. 


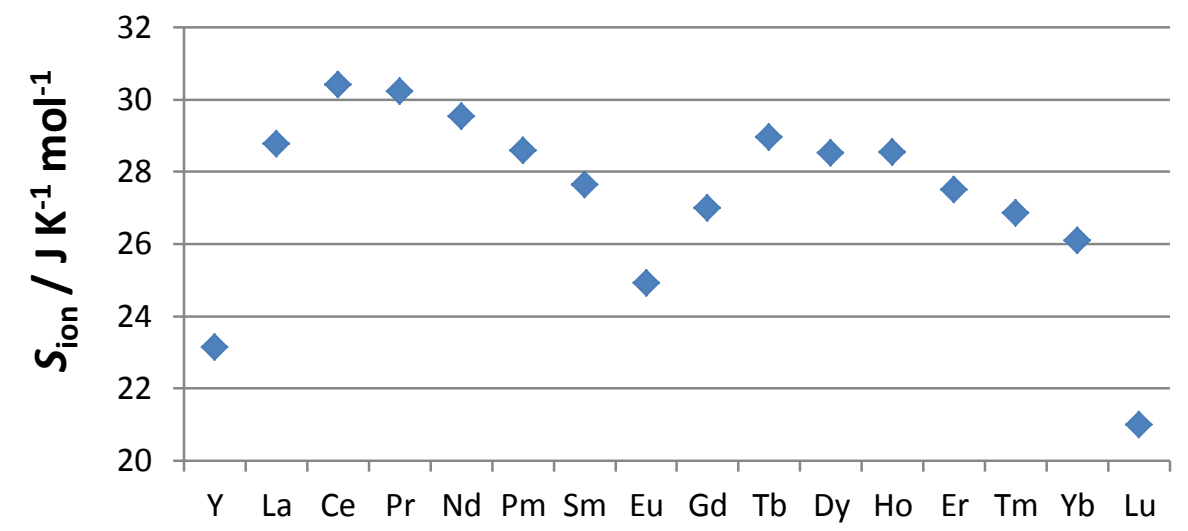

Figure S2c: Additive single-ion absolute ambient entropies, $\mathrm{S} / \mathrm{J} \mathrm{K}^{-1} \mathrm{~mol}^{-1}$, of lanthanoid garnets plotted against atomic number, with the $\mathrm{La}^{3+}$ ion value referred to an optimized self-consistent value of heat capacity [2].

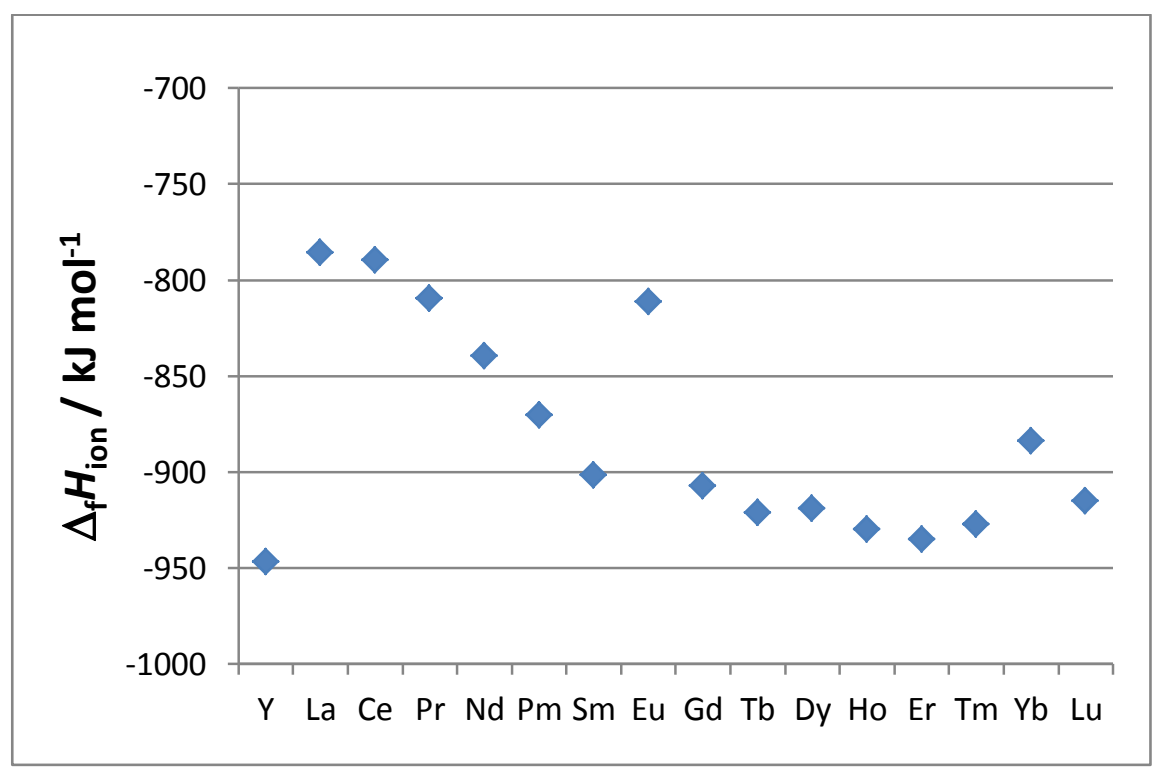

Figure S2d: Additive single-ion ambient formation enthalpies, $\Delta_{f} \mathrm{H} / \mathrm{J} \mathrm{K}^{-1} \mathrm{~mol}^{-1}$, of lanthanoid garnets plotted against atomic number, with the $\mathrm{La}^{3+}$ ion value referred to an optimized self-consistent value [3]. 


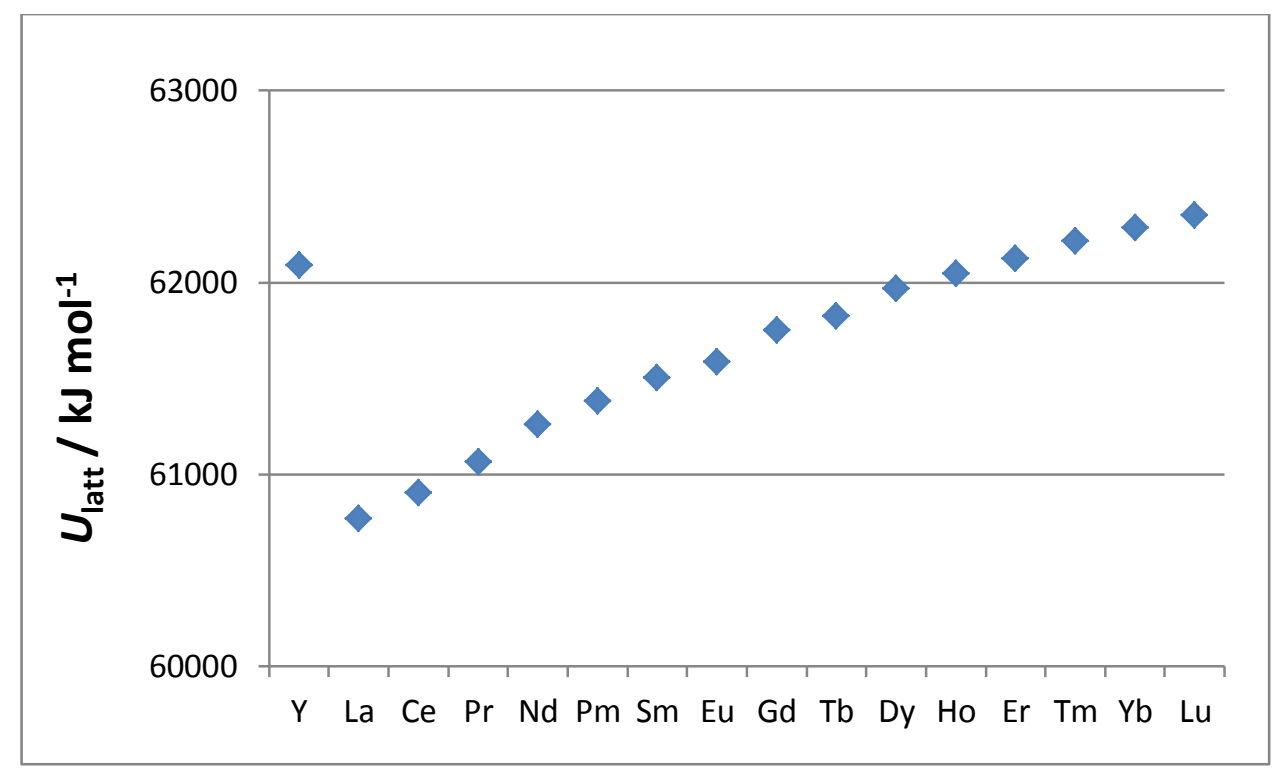

Figure S2e: Additive single-ion lattice energies, $U_{\mathrm{POT}} / \mathrm{J} \mathrm{K}^{-1} \mathrm{~mol}^{-1}$, of lanthanoid garnets plotted against atomic number.

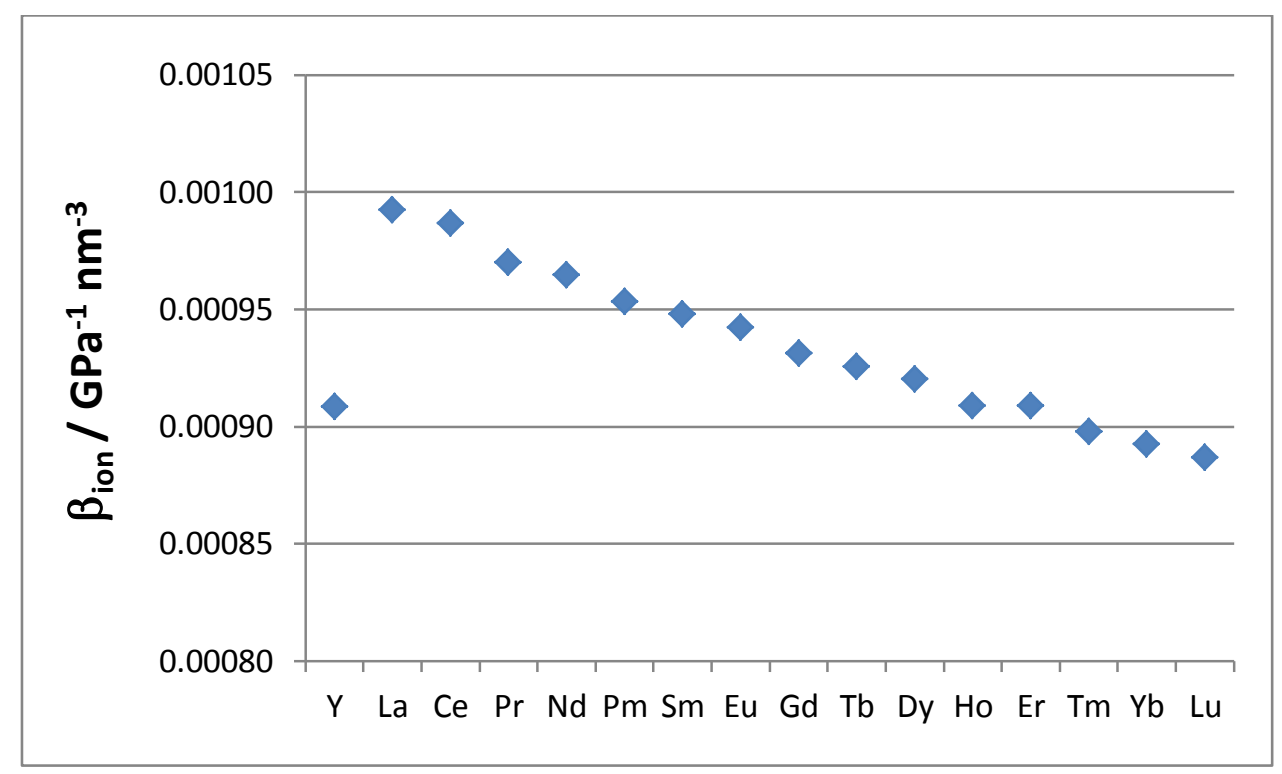

Figure S2f: Additive single-ion isothermal compressibilities, $\beta / \mathrm{GPa}^{-1}$, of lanthanoid garnets plotted against atomic number. 


\section{References}

[1] L. Glasser, H.D.B. Jenkins, Inorg. Chem. 47 (2008) 6195-6202.

[2] L. Glasser, H.D.B. Jenkins, Inorg. Chem. 51 (2012) 6360-6366.

[3] L. Glasser, Inorg. Chem. 52 (2013) 992-998. 